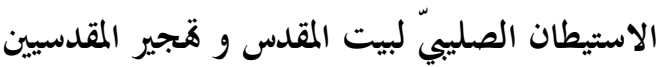

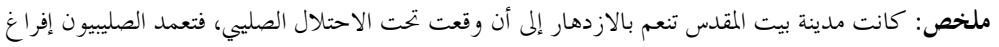

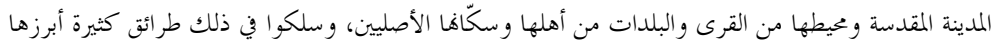

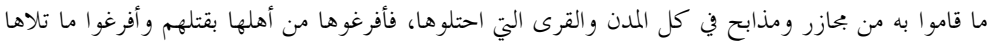

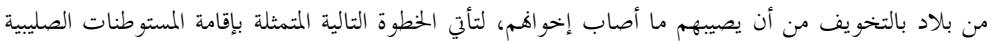

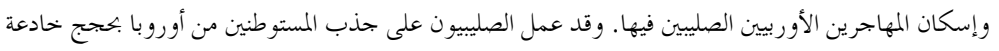

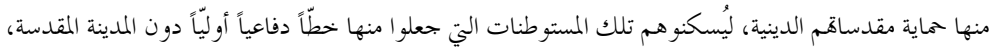

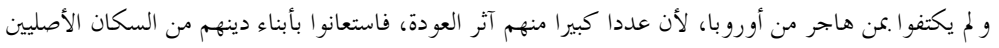

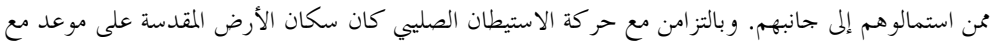

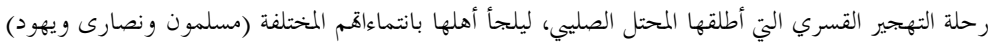

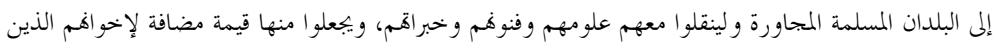

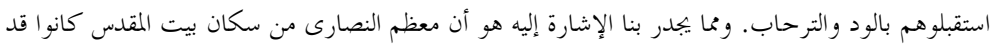

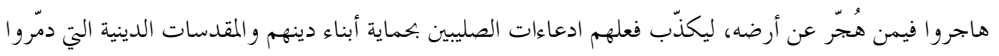

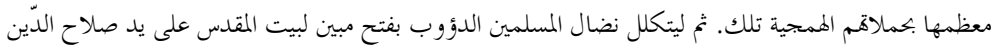

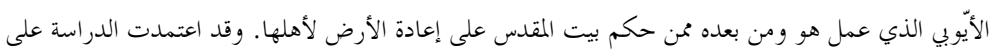

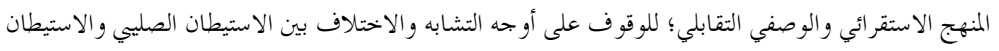

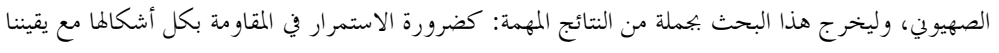

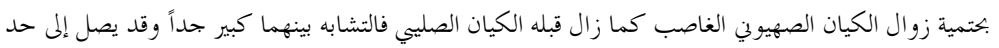

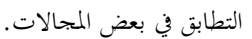
الكلمات المفتاحية: الاستيطان، بيت المقدس، التهجير، الحملات الصليبية، المستوطنات.

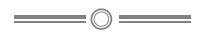

\title{
The Settlement of the Crusaders in Bayt Al-Maqdis and the Displacement of Jerusalemites
}

ABSTRACT: The city of Bayt al-Maqdis enjoyed prosperity and its people enjoyed freedom for centuries until the arrival of the Crusades. As soon as the Fatimids seized the city from the Artuqids, change seemed inevitable as the region was soon lost to the first crusade. The Crusaders deliberately evacuated the Holy City and its environs, including its villages and towns through many means, perhaps the most prominent of which was the massacres they carried out in the cities and villages 
they occupied. They began by killing its people and emptied many of their lands by spreading fear that the inhabitants' fate would be similar to that of others in cities such as Jerusalem. This was the Crusaders' first step in their settlement policy, followed by the establishment of Crusader settlements to accommodate many of the crusading European immigrants. The Crusaders attempted to attract crusaders from Europe to settle in the Holy City with deceptive arguments, including through promises to protect their holy sites. These efforts were undertaken in order to populate those settlements, which were made a primary line of defence for the Holy City. As many decided to return to Europe, in order to continue with their settlement plans, they sought to resettle indigenous Christians whom they lured to their side. In conjunction with the Crusader settlement movement, much of the original inhabitants of the Holy Land were subject to forced displacement due to the Crusader occupation, thus the original inhabitants of different religions (Muslims, Christians and Jews) would take refuge in neighbouring Muslim countries regardless of the ruling authority in these lands and carried with them their knowledge, arts and sciences, to bring added value to the places they took refuge in, as a result of which they were embraced with affection and delight. It should be noted that many of the Christians of Bayt al-Maqdis, whom the crusades claimed to be coming to protect, had to undergo forced migration from their lands, which were taken over or destroyed by the crusading barbaric campaigns. The relentless struggle of the Muslims to retake these lands culminated with their liberation by Salah al-Din, who together with his successors worked to return the land to its original inhabitants, regardless of religion. This study relies on the inductive and contrastive descriptive approach to analyse the similarities and differences between the Crusader settlement and the Zionist settlement. The article arrives at a set of important outcomes, such as the necessity to continue the resistance in all its forms, with the certainty of the inevitable demise of the usurping Zionist entity, just as the Crusader entity had become extinct before. It becomes apparent that the similarities between both entities is very great and on several important issues, reaches a point of congruence.

KEYWORDS: Jerusalem, Displacement, Crusades, Settlements.

\section{مقدمّة}

$$
\begin{aligned}
& \text { لم تكن الحمالات الصليبية على بيت المقدس وليدة الصدفة، و إنما أمر تم التخطيط و التحشيد له على مدى }
\end{aligned}
$$

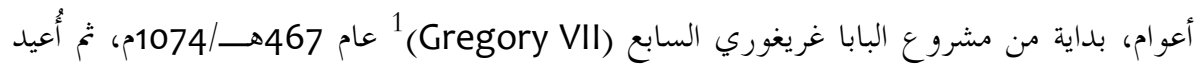

$$
\begin{aligned}
& \text { طرح فكرة احتلال بيت المقدس عسكريا من قبل الأسقف بنتسو (Pentso)، }{ }^{2} \text { لينجح البابا أوربان }
\end{aligned}
$$

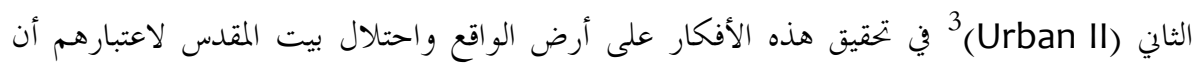

$$
\begin{aligned}
& \text { فلسطين هي ميراث مسيحي ويجب عليهم أن يستردوها بقوة السلاح، ويبدو جلياً أن هذه الحروب } \\
& \text { الصليبية بنيت على أساس ديني إضافة لما يرافقه من دو افع أخرى اجتماعية وسياسية واقتصادية، وقد } \\
& \text { كان خطاب كليرمونت للبابا أوربان عام 488هــ/1095م هي الصيغة النهائية والصريحة لفكرة } \\
& \text { الاستيطان الصليي، قال: }
\end{aligned}
$$


لأن هذه الأرض التي تعيشون عليها محاطة بالبحر من كل جانب وتحوطها سلاسل الجبال، وتضيق

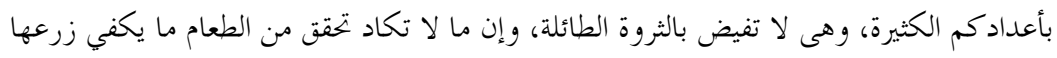

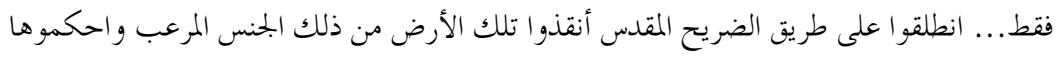

\section{المشكلة البحثية}

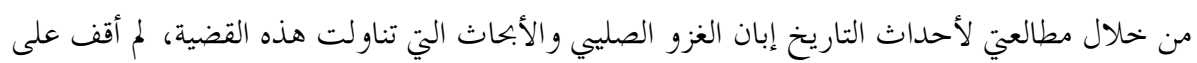

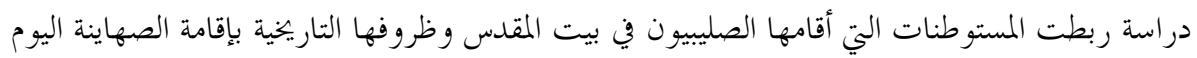

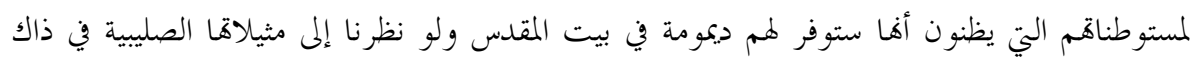

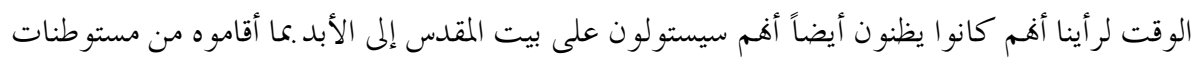

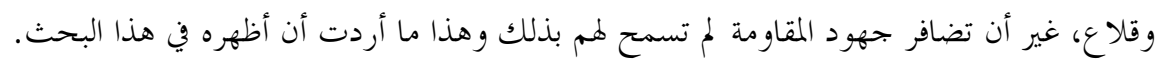

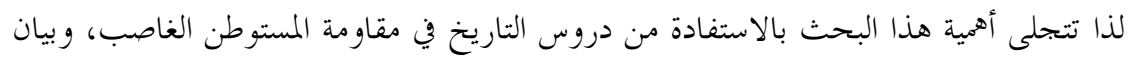

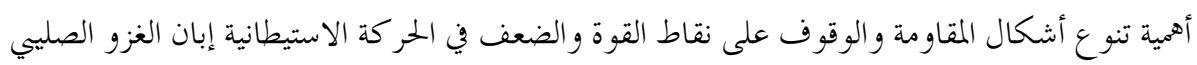
لبيت المقدس، لإجراء مقابلة بينها وبين الحركة الاستيطانية الحديثة من قبل الصهاينة.

أهداف البحث إننا إذ نبحث في الموضوع فإننا هدف من بحثنا أن نستنطق التاريخ في السياسة الاستيطانية للمحتل في

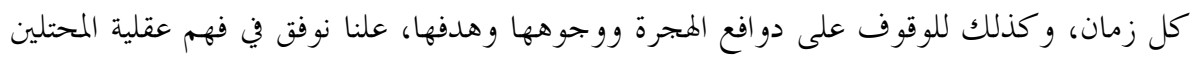

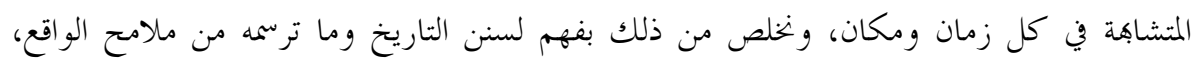

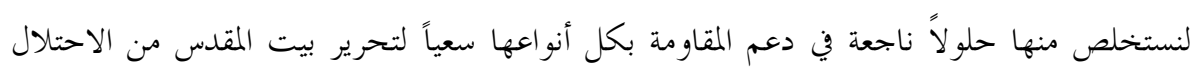

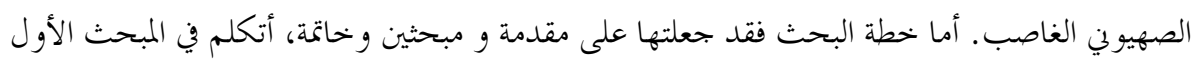

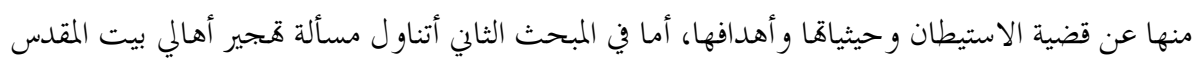

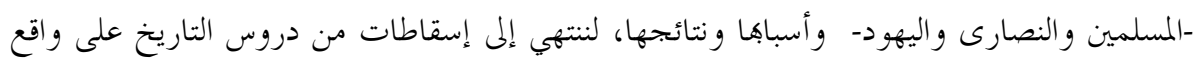

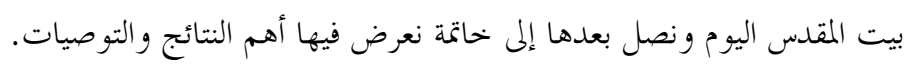

: المبحث الأول: قضية الاستيطان وحيثياما وأهدافها أولاً: العناصر الأساسية للاستيطان الصليبي

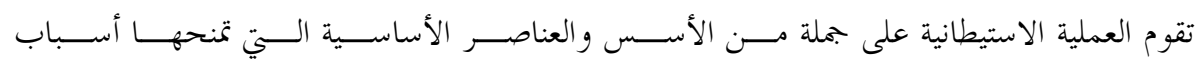

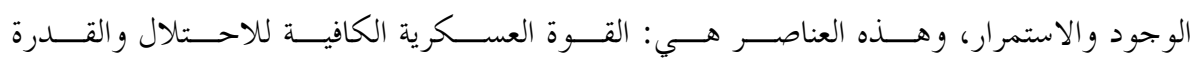


الاقتصادية لتمويلها وقبلهما الأرض الصالحة للاستيطان و القـــوة البشـــرية بمعــنى السّــــان لأنــــم

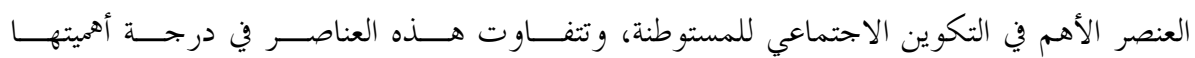
وارتباطها بديمومة الاستيطان واستمر اريته، و سيتم ذكرها بشيء من التفصيل مع مر اعاة أهميتها.

\section{1- الأرض} تُعدُّ الأرض العنصر الأهم في إقامة أي تجمع بشري، فلا شك أها نقطة البداية التي من أجلها تقام المخططات وتجهز العناصر الأخرى. وقد بدا ذلك جلياً في خطب القساوسة والرهبان والباباوات التي

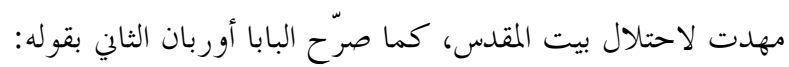
أنقذوا تلك الأرض من ذلك الجنس المرعب واحكموها بأنفسكم لأن هذه الأرض التي تفيض باللبن والعسل كما يقول الكتاب المقدس "أعطاها الرب ملكًا لبين إسر ائيل". 5

و من أجل هذه الأهمية كان لابد لهم من إضفاء قداسة عظيمة على هذه البقعة الجغرافية من الأرض لحشد الجماهير وتوجيه القوى الأخرى للتضحية في سبيلها. وهذا ما عملت عليه المرجعيات الدينية الصليبية تمهيداً لإقامة عناصر الاستيطان الأخرى، فاتخذت من النصوص التي وردت في الإبجيل عن هذه الأرض وضرئ وقدسيتها على أها ميراث السيد المسيح لهم لذا و جب عليهم أن يخلصوها من سيطرة المسلمين بالسلاح كما عبر عنه البابا أوربان الثاني بقوله: "يجب أن تدفعوا بالسلاح عن حرية أرض الآباء حقاً وعدلاً". 6 ومما سبق أعلاه يظهر لنا جلياً أن الحروب الصليبية لم تكن دينية فحسب وإنما كانت حركة استعمارية استيطانية هدفها التوسع الجغرافي للغرب الصليي و السيطرة على الأرض في الشرق، مع تسترها بغطاء ديني صليي. وقد ذهب إلى تأييد هذا القول عدد من المؤرخين في الغرب، 7 منهم: برنارد لو يس (Bernard Lewis) و جرو سيه (Trevelyan) (Grousset) و تريفليان (إضافة إلى هنري وليم كارلز ديفز الذي في كتابه (أوروبا في العصور الوسطى) إذ قال متحدثاً عن الحروب الصليبية تحت عنوان الاستعمار الأوربي: وليم

إن الشغل الشاغل للحكام اللاتين في الثمانين سنة التي أعقبت تأسيس المستعمرات الأوروبية في الأرض المقدسة هو توسيع حدود تلك المستعمر ات وتدعيمها تحت تاج بيت المقدس. 8 يتضح مما سبق أن السيطرة على الأرض واحتلالها كان الهدف الأهم والعنصر الأبرز في الحركة الاستيطانية الصليبية لبيت المقدس، وأن إضفاء القداسة على هذه الأرض وإسقاط نصوص الإبخيل عليها كان تمهيداً لانتقال إلى العنصر الثاني. 
لا شك أن القوة العسكرية هي الركن الأساسي في الاستيطان الصليي، فهي العامل الأساسي في السيطرة

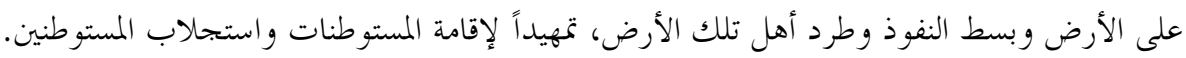

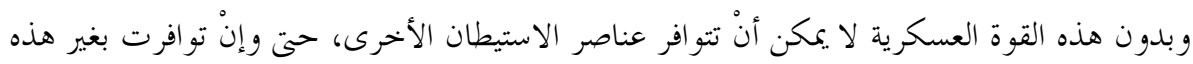

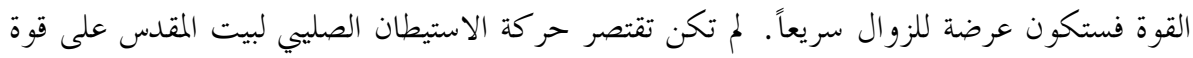

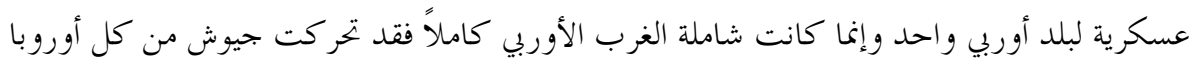

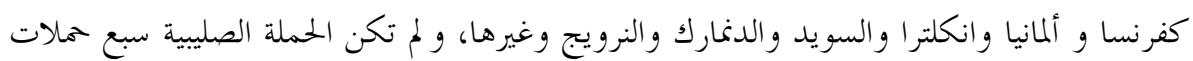

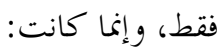

مدادًا لا ينقطع، وسيلاً من البشر يتحرك على السفن وفي البر؛ مدار السنوات المائتين التي امتدةًا

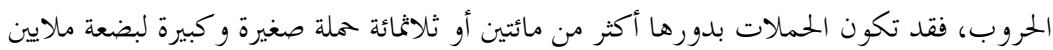

$$
\text { بعضهم ححاج وبعضهم محار بون وكثير منهم بتحار ومغامرون. }
$$

لقد قامت مستوطنات الصليبين على يد جيش صليبي وقوة عسكرية من كل أوروبا، عملت على

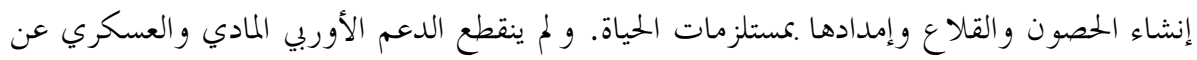

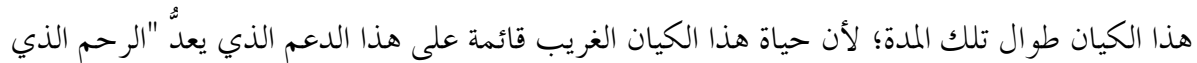

$$
\text { 3- منه ولد المشروع الفرنجي الصليي". } 10
$$

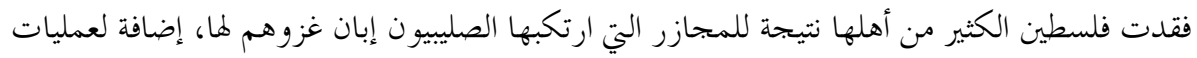

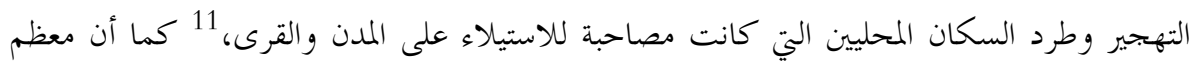

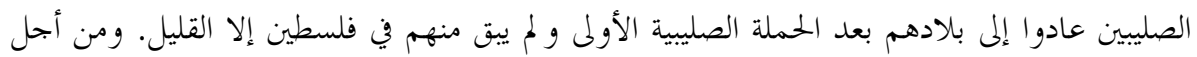

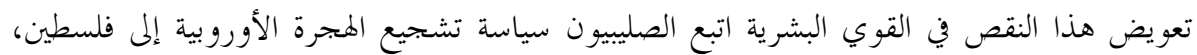

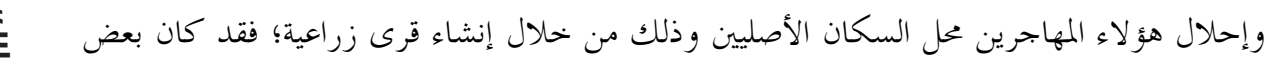

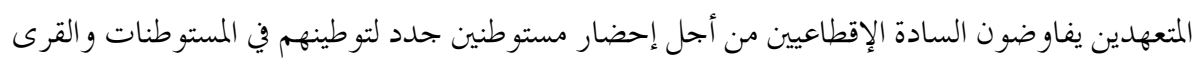

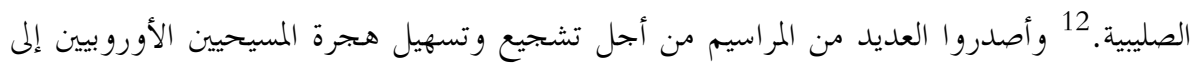

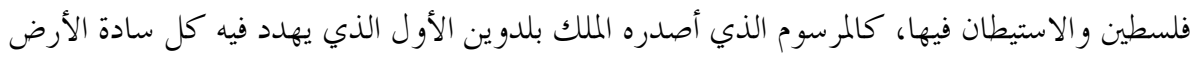

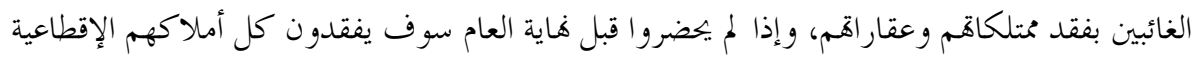

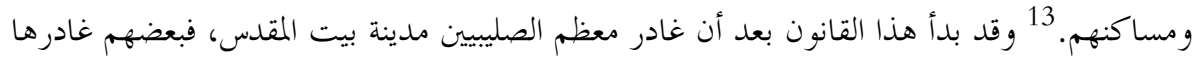
إلى المدن الساحلية التجارية التي تم الاستيلاء عليها، بينما ذهب البعض الآنر بلدر إلى الأرياف مع أسيادهم 
الإقطاعيين. ${ }^{14}$ ما جعل الأمير جودفري يتنبه إلى حجم الخطورة الأمنية والاقتصادية التي قد تتعرض لها

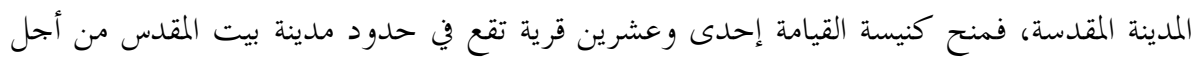

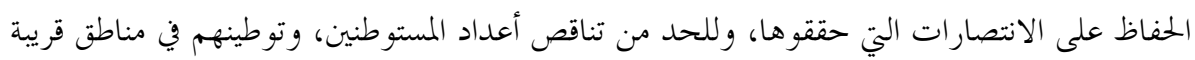

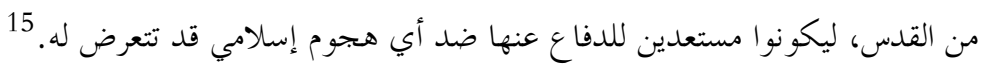

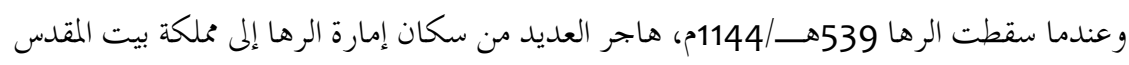

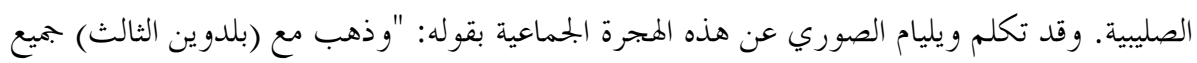

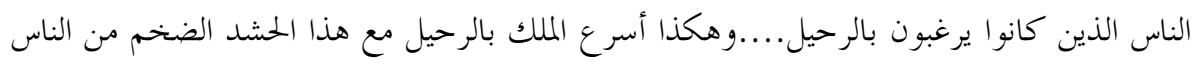

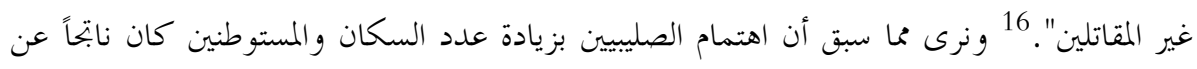
شعورهم بأهمية العنصر البشري في إقامة مستوطناهم وحمايتها، فالعنصر البشري هو المكون الأساسي الماسي للقوة العسكرية والقوة الاقتصادية والدعم المالي.

\section{4- القوة الاقتصادية}

تعدّ القوة الاقتصادية والمالية من العناصر الأساسية والمهمة في الاستيطان وذلك من أجل تحمّل نفقات

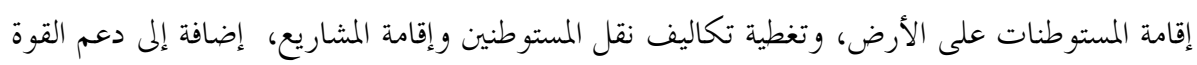

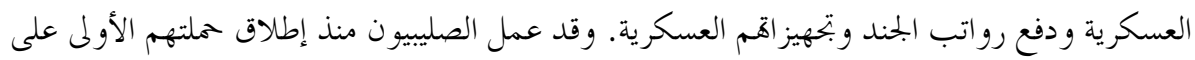

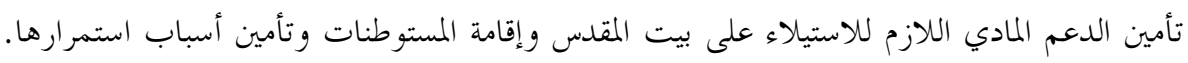

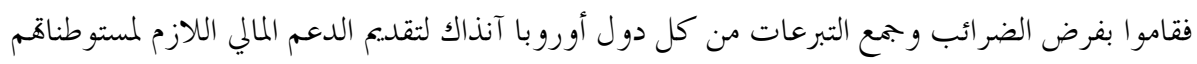

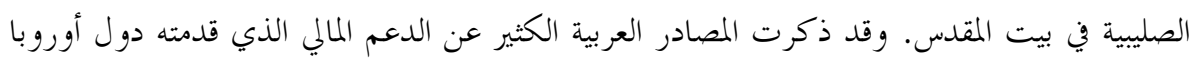

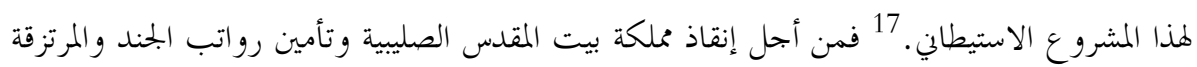

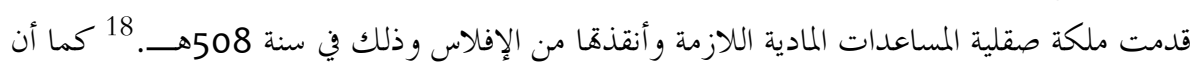

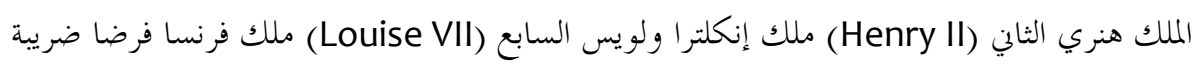

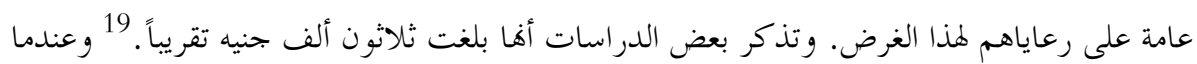

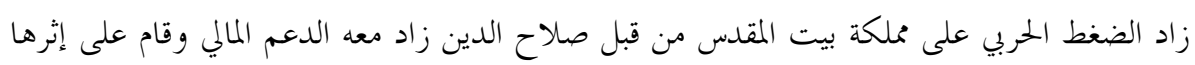

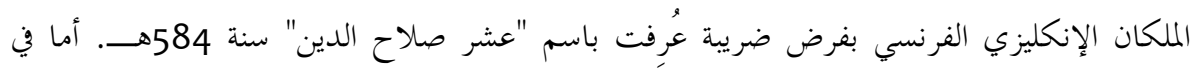

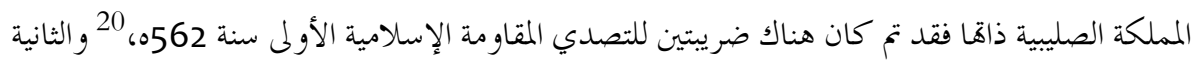

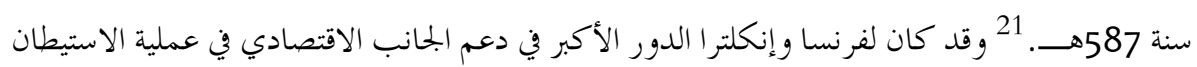
الصليي لبيت المقدس. 


\section{ثانيا: الإجراءات التي اتخذها الصليبيون لاستيطان بيت المقدس}

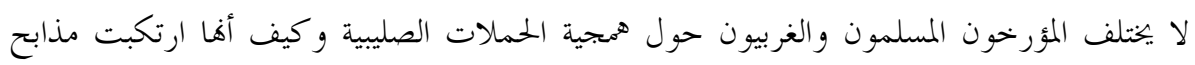

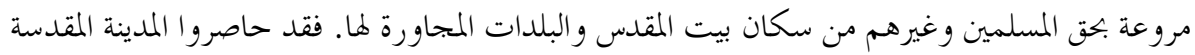

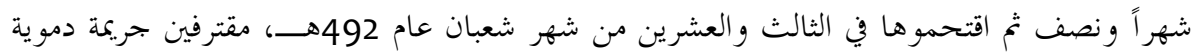

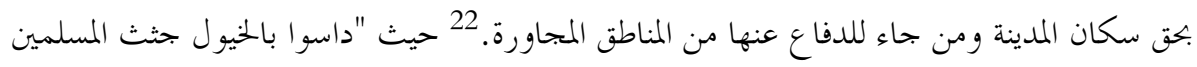

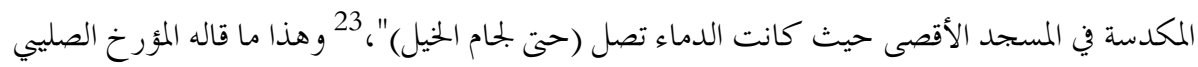

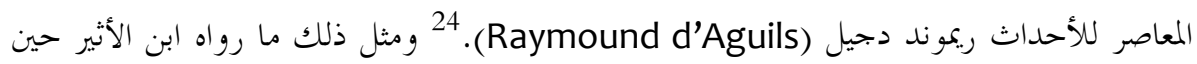

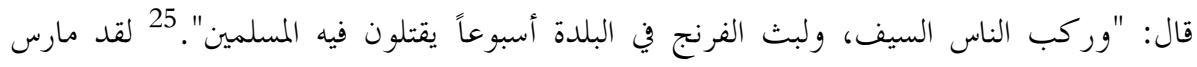

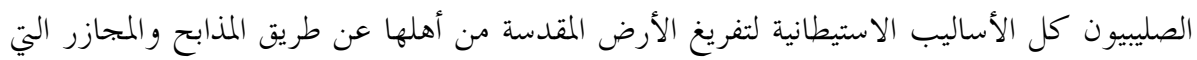

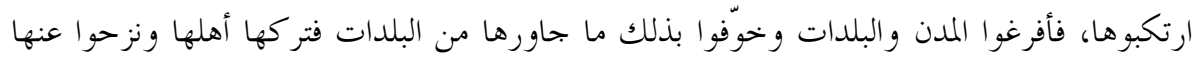

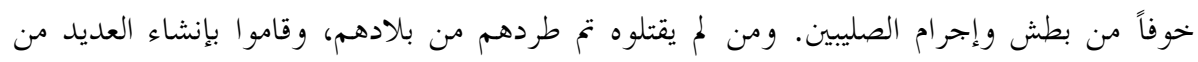

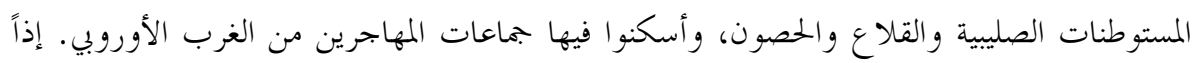

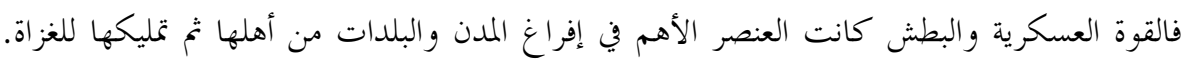

يقول المؤرخ فوشيه الشارتري:

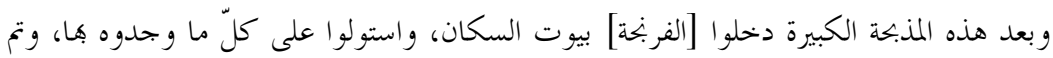

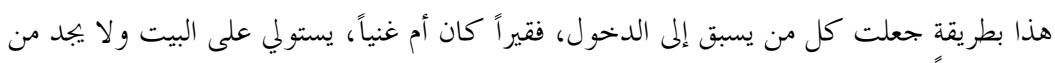

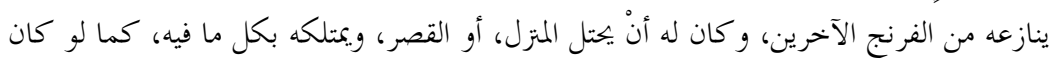

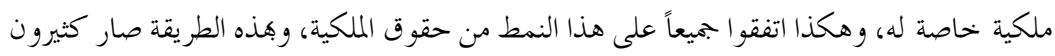
من الفقراء أغنياء. ومع ذلك فإن عملية الاستيطان الصليي في القدس اعترضتها منذ البداية مشكلة نقص العنصر

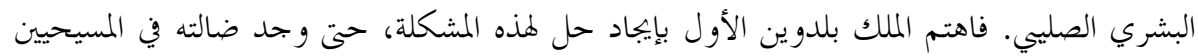

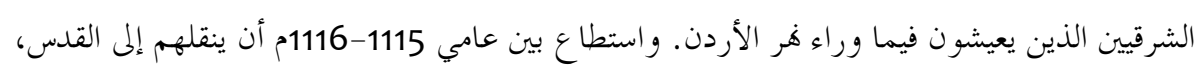

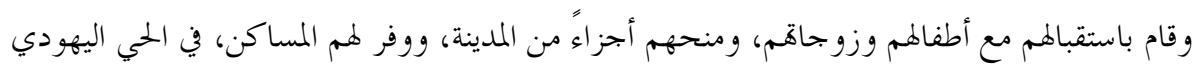
الذي كان يقطنه اليهود قبل المجزرة التي ارتكبها فيه الصليبيون. 27

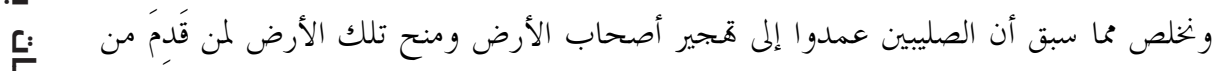

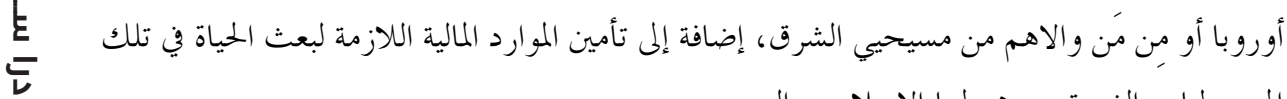


ثالثا: المستوطنات الصليبية حول بيت المقدس

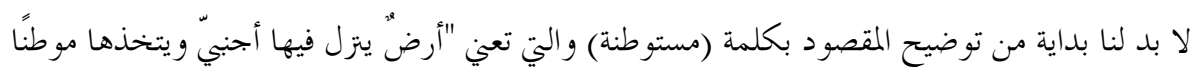

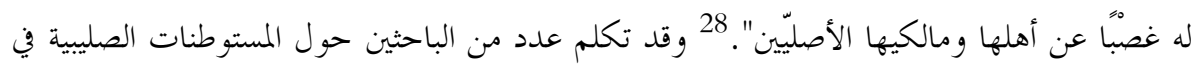

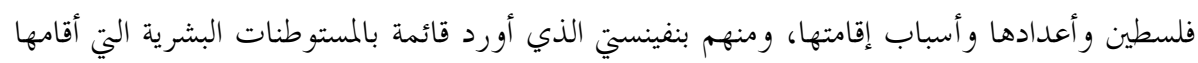

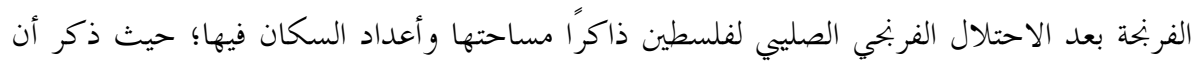

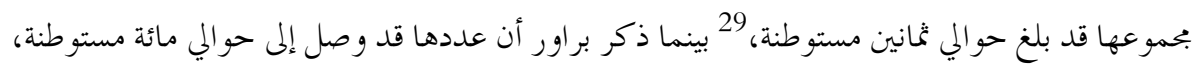

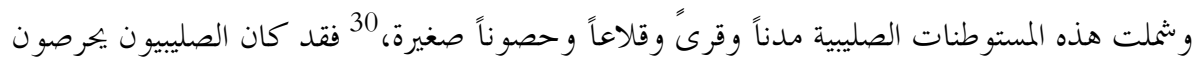

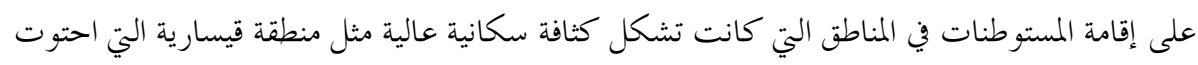

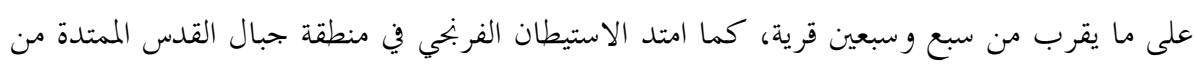

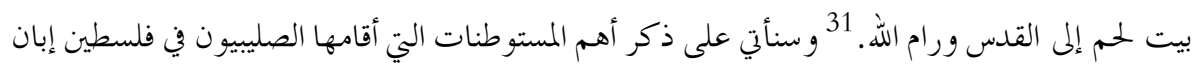

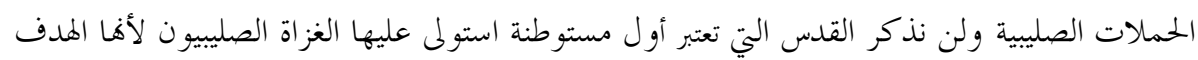

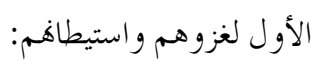

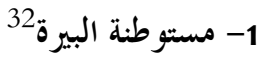

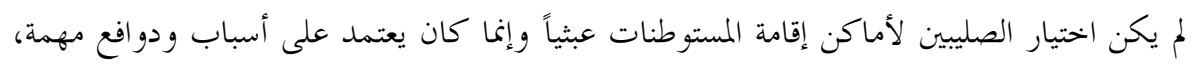

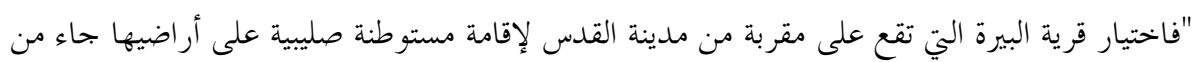

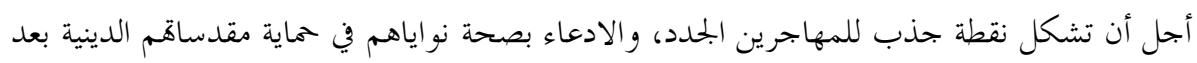

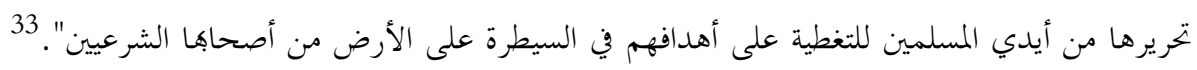

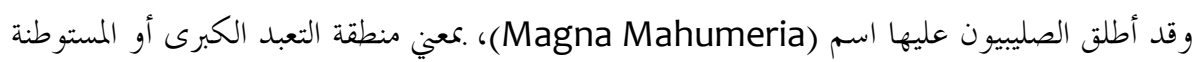

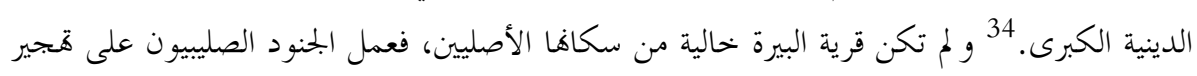

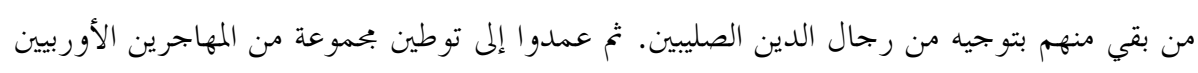

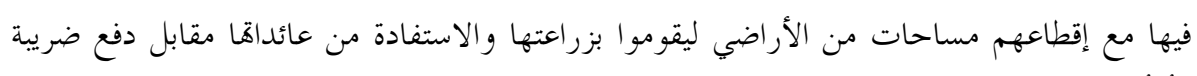

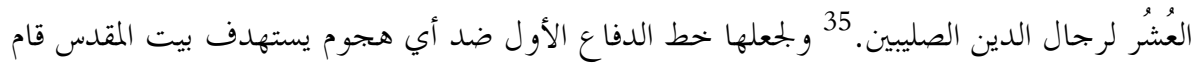

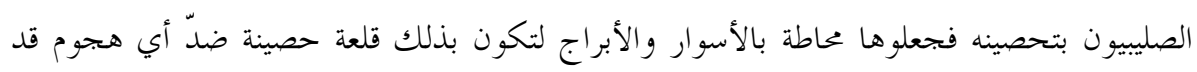

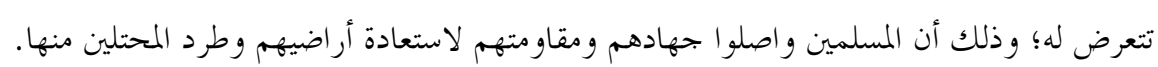

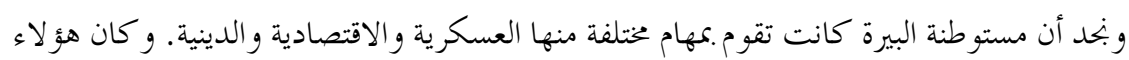

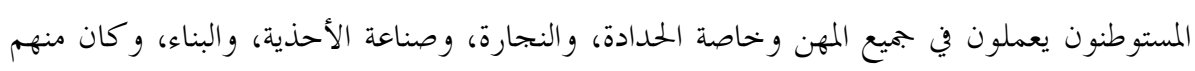


الصاغة، والمزارعون الذين كانو ايشرفون على الحدائق والبساتين. وقد قام رجال الدين اللاتين بتنظيم المجتمع الزراعي في البيرة وغيرها من المستوطنات التي أقاموها في فلسطين.

2- مستوطنة القبيبة36

أقام الصليبيون مستو طنة القبيبة وأطلقو ا عليها اسم المحمرة الصغرى (Prava Mahumeria)، أشارت

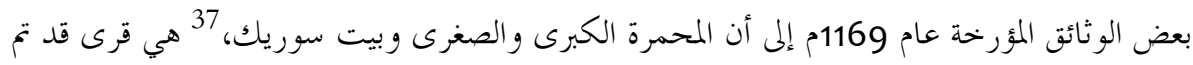

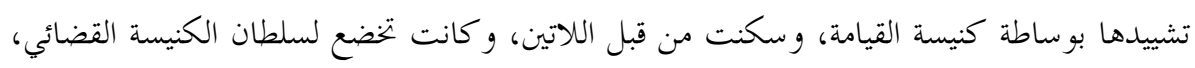

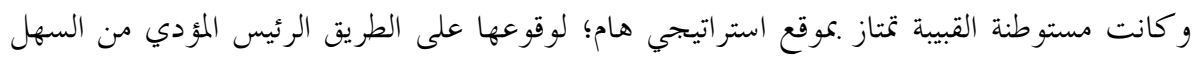

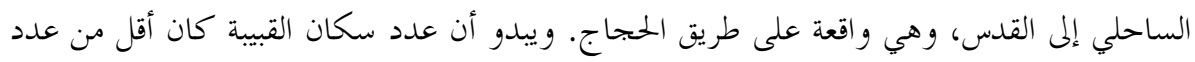

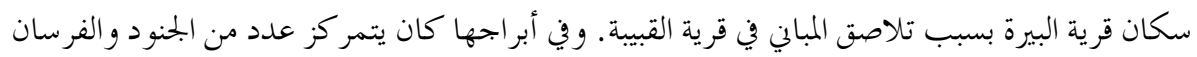

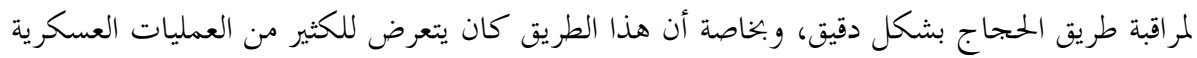

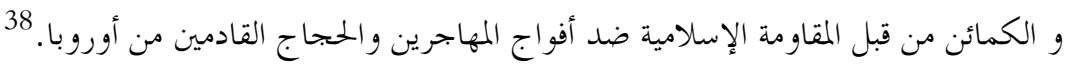

\section{3- - 3ستوطنة راماتيس}

ولاستكمال خطوط الدفاع حول مدينة القدس أقام الصليبيون مستوطنة راماتيس (Ramathes) على رانيس

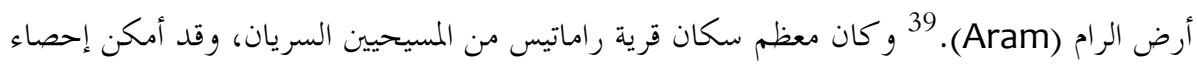

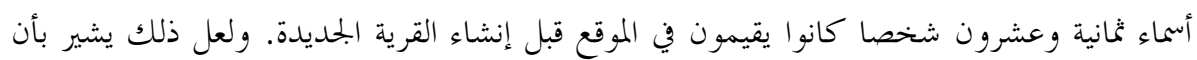

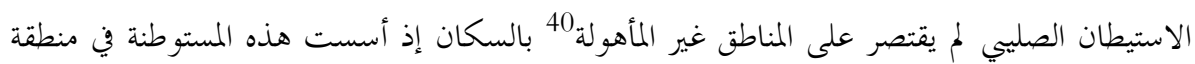
مأهولة بالسكان.

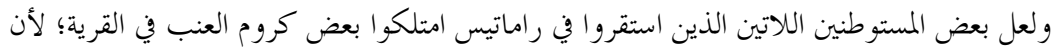

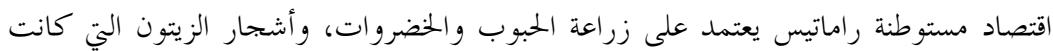

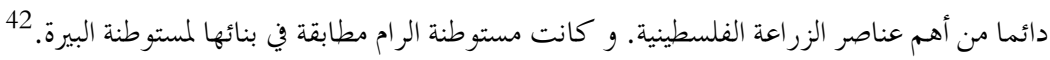

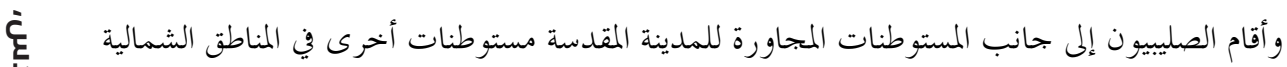

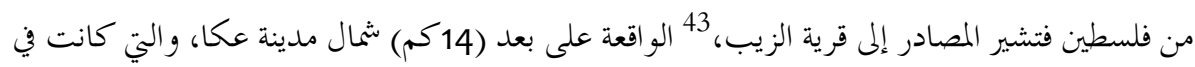

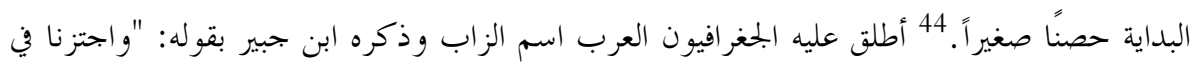

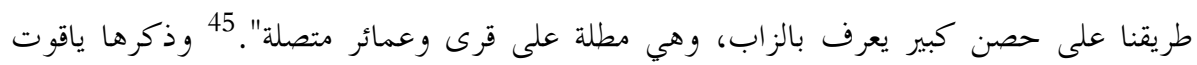

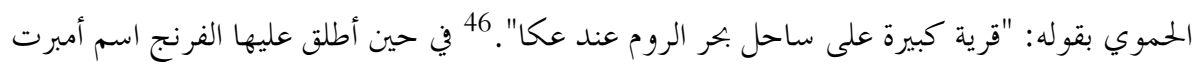
وذلك نسبة إلى الفارس الفرنجي الذي احتلها 493هــ/1104م. 
فإن عدد المستوطنات الصليبية زاد عن الثمانين حتى أوصله بعضهم إلى مئة. كل ذلك في سبيل تثبيت وجود المحتل الصليي في هذه الأرض علّه يحقق شيئاً من الأسباب المادية المعينة على استمر ار وجودهد فيها.

\section{رابعاً: أثر الاستيطان على المعالم الإسلامية في بيت المقدس}

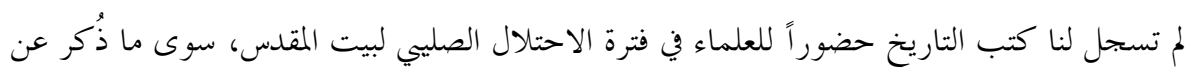

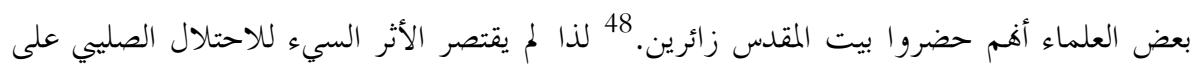

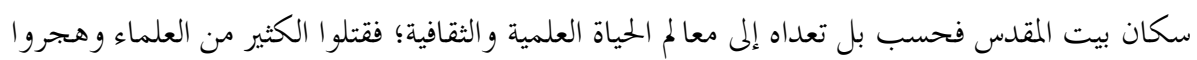
من لم يقتل منهم، و بذلك تم القضاء على الحركة العلمية و الفكرية. كما هاجم الصليبيون أماكن العبادة الإسلامية ودمروا المساجد وحولّوا بعضها إلى كنائس، فما أن سقط المسجد الأقصى بين أيديهم عام 493هـــ حتى عملوا على تحويل أجزاء كبيرة منه إلى استخداماهم، فجعلو ا قبة الصخرة كنيسة سمّوها

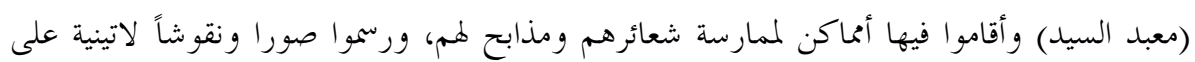
جدر انه و كذلك وضعو ا فيه التماثيل. 49 أما الجامع الأقصى فجعلوه مسكناً لملكهم ولفرسان الداوية. 50

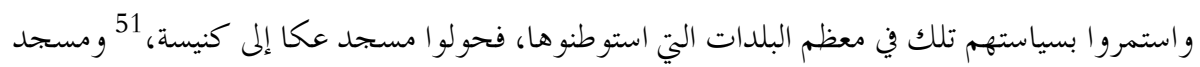
عسقلان أيضا و الذي اطلقوا عليه اسم (كنيسة القديس بولس)، وحولوا المسجد الإبر اهيمي في الخليل إلى كنيسة أيضاً. 52 وكان الهدف من هذه السياسة هو القضاء على الوجود و الهوية الإسلامية ومعالمها و كل مظاهر الحياة العلمية فيها. 53 وإمعاناً في تطبيق سياسة الاضطهاد الثقافي والحضاري ضد المسلمين؛ غيّ الصليبيون أسماء أبو اب بيت المقدس، و شوارعها، وأسماء بعض الأماكن فيها، وأطلقو اعليها أسماء صليبية جديد. 54 نتيجة لما سبق لم يهتم الصليبيون بإنشاء المدارس بل عملوا على تعطيل الحياة العلمية

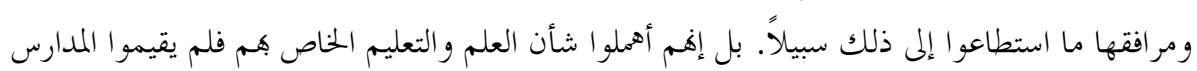

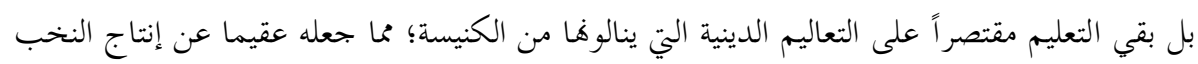
العلمية من المفكرين والمجددين، مما أوقعهم في التخلف الفكري الذي حرم المجتمع من الاستفادة من تلاقي حضار ات مختلفة.

\section{خامساً: المقاومة وفهاية الاستيطان الصليبي لبيت المقدس} بخح الصليبيون في احتلال أرض بيت المقدس وفلسطين وإقامة المستوطنات فيها، وذلك نتيجة لجملة من الأسباب؛ كانقسام الصف الإسلامي وفقد القيادة الموحدة وضعف الأمة بشكل عام وتناحرها مذهبياً.

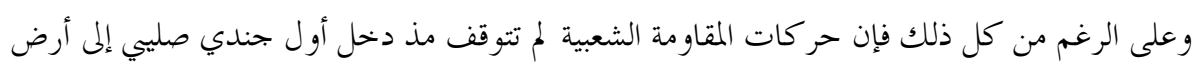

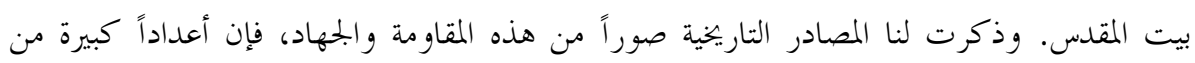


المجاهدين دافعوا عن بيت المقدس من أهله ومن سكان الريف المجاور له الذين لجؤوا إليه لصد هجوم

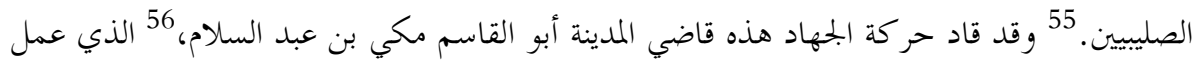

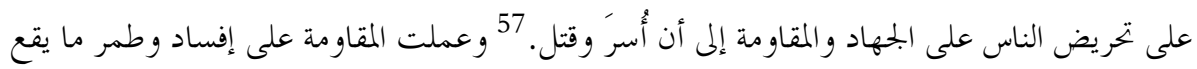

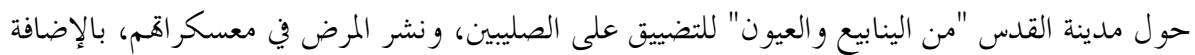
إلى تدمير صهاريج وأحو اض مياه الأمطار. 58 دفعت هذه المقاومة الشعبية والإسلامية بأساليبها المتنوعة بأعداد كبيرة من الصليبيين إلى مغادرة

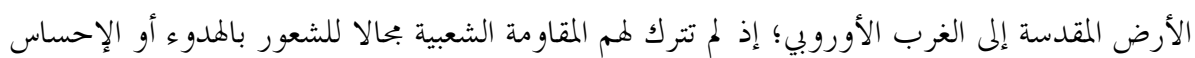

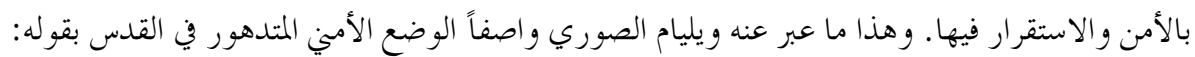

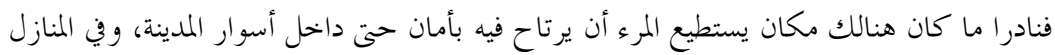

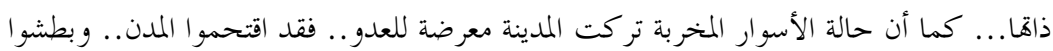
بالكثيرين في عقر مناز لهم.

هذا الرعب الذي وقع في نفوسهم دفع بعضهم للعودة إلى بلداهم التي قدموا منه. كما أن المقاومة لم

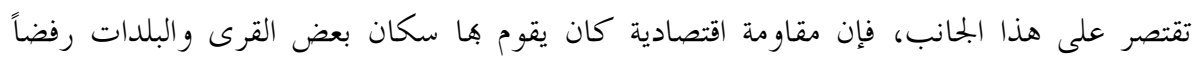

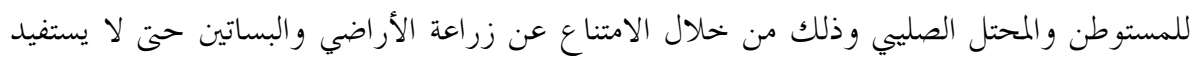

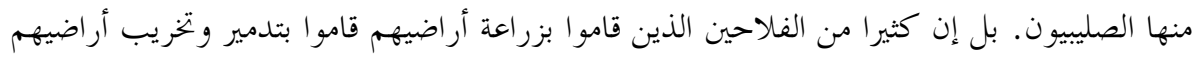

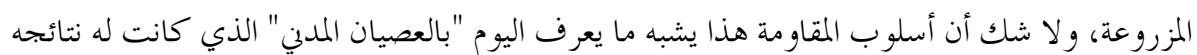
السلبية على الاقتصاد الصليي.

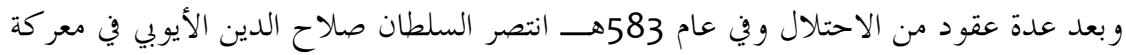

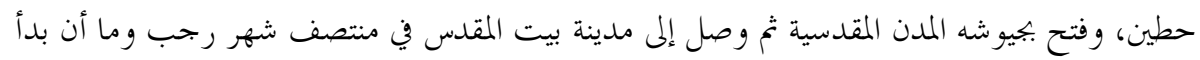

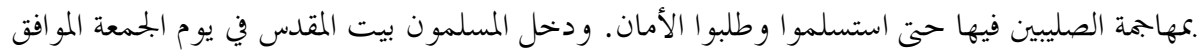

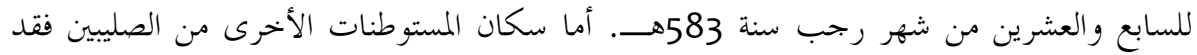

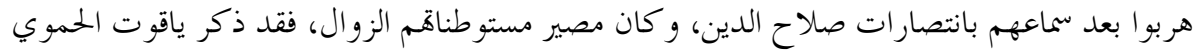

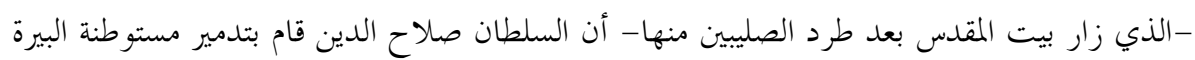

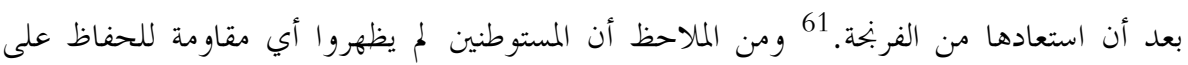

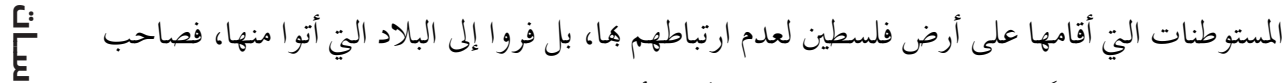

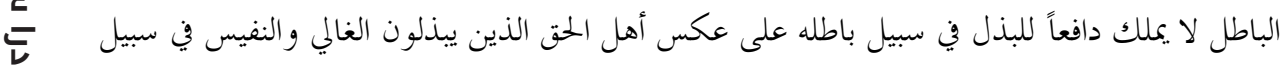


المبحث الثاني: قجير أهالي بيت المقدس (المسلمين والنصارى واليهود) أسباها ونتائجها

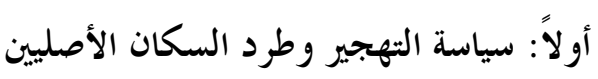
كان للاستيطان الصليي أثره على البنية السكانية لفلسطين وبيت المقدس، مما جعل هذه "البنية الفسيفسائية" والتي تشمل المسلمين و اليهود و النصارى على اختلاف مذاهبهم في حالة نزوح وعدم الئيه استقرار؛ فالمذابح والمجازر التي ارتكبها الصليبيون ضدهم وعمليات الطرد والتهجير المرافقة لسياسة الاستيطان وإعادة التوطين، أدت إلى تغيرات في هذه البنية السكانية. و بقيت آثار المجازر والمذابح الصليبية المروعة محفورة في ذاكرة الجماهير وأرغمتهم على الهروب. كل ذلك يشير بكل وضوح إلى إلى سياسة التهجير القسري الذي اعتمده الصليبيون؛ فقد رافقت الحملة الصليبية الأولى عمليات فجير وهجرة لعدد كبير من السكان؛ كما حدث تفريغ سكاني لبعض المناطق والمدن، وهرب سكان المناطق التي تعرضت للعدو ان إلى مناطق أخرى أكثر أمنًا. فتؤ كد معظم المصادر التاريخية المتوفرة بشكل و واضح أن موجات كبيرة من اللاجئين طردوا وهجروا من مدهم وقراهم أثناء العمليات العسكرية للقوات الصليبية لاحتلال الأرض المقدسة حتى كادت فلسطين تخلو من سكاها الأصليين الذين تفرقوا في بلاد المسلمين. ويصور لنا المؤرخ فوشيه الشارتري ذلك بقوله: "كان المواطنون الشرقيون قد ولوا الأدبار لما سمعو الشائعات .مقدمنا، و لم يبق إلا أولئك الذين فاقوا الهباب سو اداً فتر كناهم، وعاملناهم باحتقار ". 62 و يقصد بهم أولئك البؤساء و الضعفاء الذين كانت أوضاعهم صعبة و لم يستطيعو ا الخروج. وسنأتي على لى ذكر عناصر البنية السكانية ( المسلمين والنصارى واليهود) و وموقف الصليبين منها:

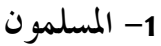

تعرض المسلمون في فلسطين للطرد و التهجير من قراهم وبلداهم كما ذكرت بعض وثائق كنيسة القيامة؛ وذلك ضمن سياسة الاستيطان وتفريغ القرى والأراضي ومنحها للكنائس والأديرة. ومن ذلك فجير

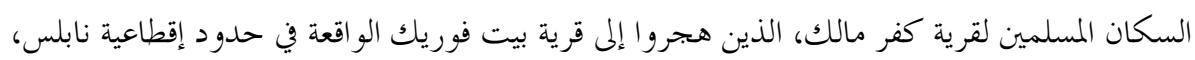
وذلك من أجل منح قرية كفر مالك إلى كنيسة القيامة.63 وعندما فرض الملك بلدوين حصارا بريًا

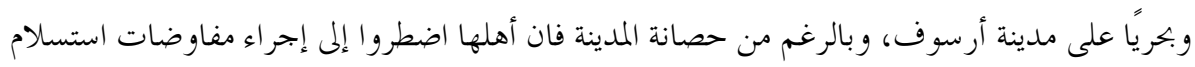

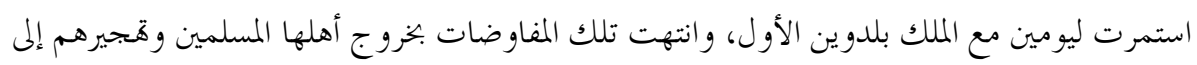
مدينة عسقلان وعلى ذلك دخل الصليبيون مدينة أرسوف في 28 جمادى الأول 494هــ. 64 ومن الجحير بالذكر أن أساليب التهجير أو طرد سكان فلسطين من بلداتهم وقر اهم كانت متنوعة؛ فعندما اقتربت القوات الصليبية الغازية من فلسطين، وسمع أهلها بالجر ائم والمجازر التي ارتكبتها قواهم ضد المسلمين في أنطاكية ومعرة النعمان وجد سكان بعض المدن غير المحصنة أنفسهم بحبرين على 
الخروج منها. و لم يقتصر نزوح السكان عن المدن غير المحصنة فحسب بل إن أهل الريف الفلسطيني

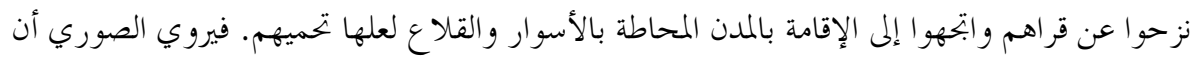

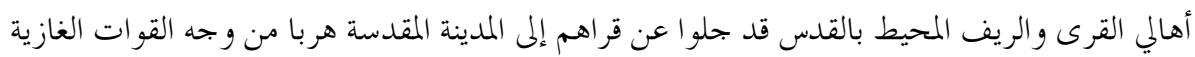
وبحثا عن السلامة لأنفسهم.

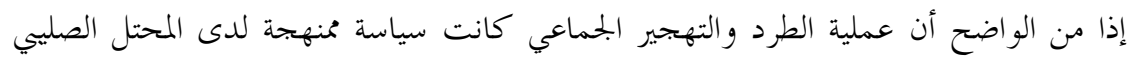

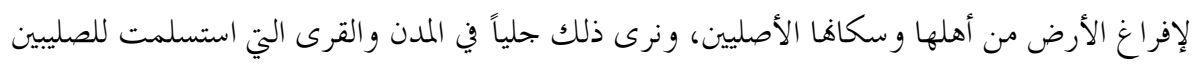

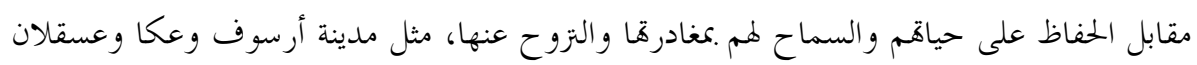

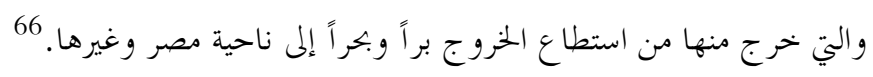

2- النصارى

كان المسيحيون الشرقيون بكافة طو ائفهم يقيمون في مناطق عديدة من فلسطين، وقد مثل هؤلاء الطبقة

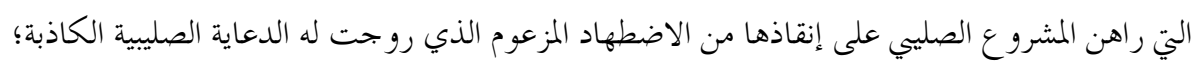

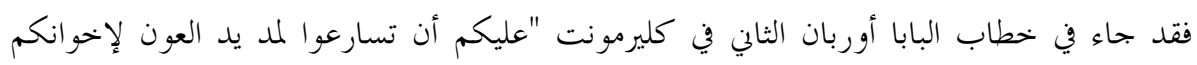

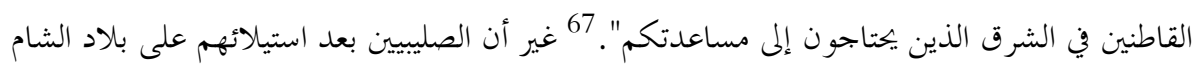

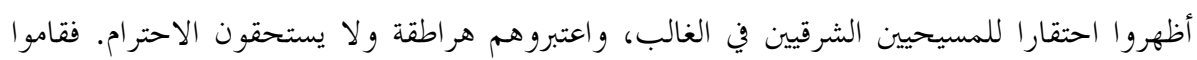

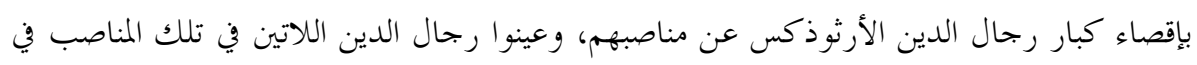

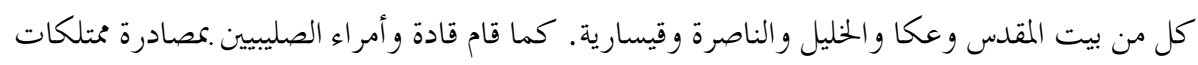

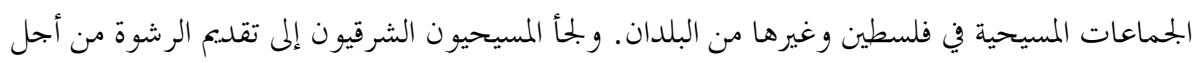

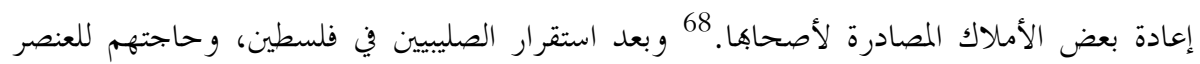

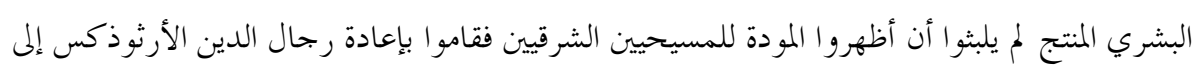
كنيسة القيامة، وسمحوا لهم .مباشرة طقوسهم الدينية.

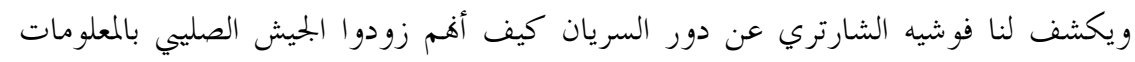

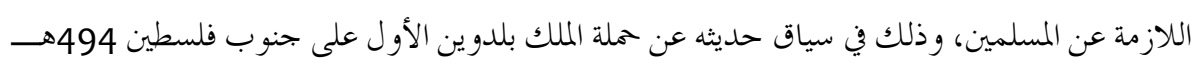

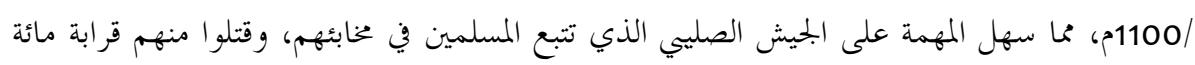

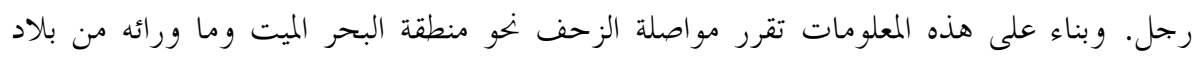

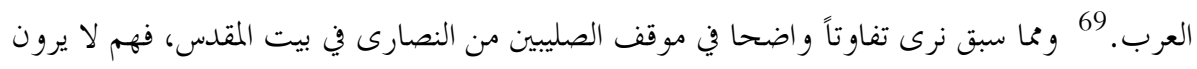

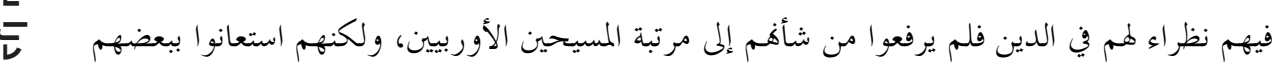


من والاهم في حملاهم ضد المسلمين، وكذلك استخدموهم عند حاجتهم للعنصر البشري في إقامة المستوطنات الصليبية.

\section{3- اليهود}

في أو اخر القرن الخامس الهجري بدأت التجمعات اليهودية في بلاد الشام تقل وتنحصر في مراكز محددة، حيث يحددها أحد الباحثين بعشر بتمعات موزعة على المدن الساحلية الكبرى، وفي الرملة وطبرية و القدس. و يبدو أن ذلك راجع لأنباء المذابح والمجازر المرتكبة في الغرب ضد اليهود، وقرب وصول الصليبيين إلى بلاد الشام. 70 هذا بالإضافة إلى الخطابات و التحذيرات التي وصلتهم من إخو اهمم سواء في الغرب الأوربي أو في المشرق الإسلامي تحذرهم من الصليبيين. ففي أعقاب وصول الصليبيين إلى الساحل اللبنائ عام 493هــ، وصل خطاب من مدينة رفح، بصحبة أحد سكاها من اليهود يطلب من إخوانه اليهود في مدينة القدس أن يهربو إلى مدينة عسقلان خوفًا من الخطر الصليي. 71 وهو ما يفسر لنا أسباب الهجرة الجماعية التي قامت هها الجماليات اليهودية من بعض المدن الهامة مثل رام الله و يافا هربًا من الخطر الصليي القادم من الغرب الأوروبي. 72 وتوجه كثير منهم إلى حلب 73 ودمشق حيث و جدت حات حارة

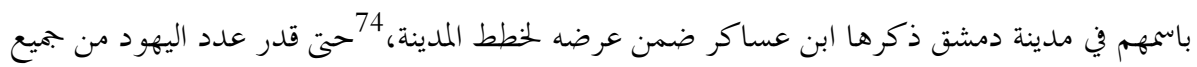
الطو ائف فيها بحو الي عشرين ألف يهودي. 75 وذكر التطيلي عددهم أثناء زيارته لدمشق بحو الي (3600) يهودي. 76 كما هاجر عدد من اليهود إلى مصر حيث ذكر التطيلي وجود كنيسان لليهود في القاهرة إحداهما "ليهود فلسطين ويسمى كنيس الشاميين"، هكذا نرى أن كثيرًا من اليهود قد هجرو إندئ فلسطين إلى مصر، والمدن الشامية الداخلية قبيل أو بعد الاحتلال الصليي للأرض المقدسة.

\section{ثانيا: دورة التاريخ بين الحر كة الصليبية والصهيونية}

إن قضية التطابق بين قضيتين تاريخيتين تختلفان من حيث الظروف الدولية ليس وارداً، لكن التشابه أمر ممكن بل واقع أيضاً. ومع وجود من يرى أنه لا وجهه، أو لا حاجة -بتعبير أدق - للمقارنة بينهما لاختلاف الظروف التي أفرزت كلاً منهما، إلا أن هناك من يرى بينهما تطابقاً أو تشاهاً كبيراً جداً.

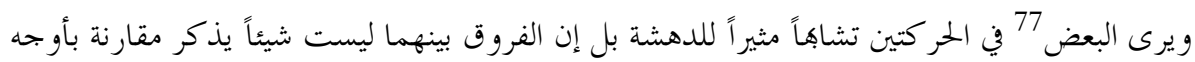
الشبه المثيرة. فيذكر أحد الباحثين: بعد يومين من نكسة يونيو 1967، و بالتحديد في 7 يونيو أعلن دولة الكيان الصهيو لي احتلالها مدينة

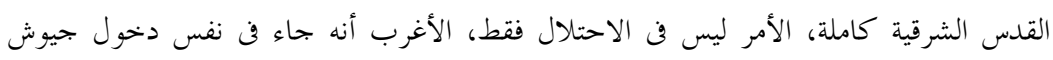

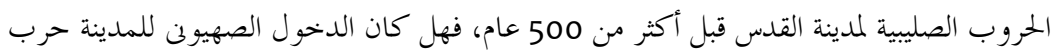
صليبية جديدة، وما أوجه التشابه بين الواقعتين؟ إن هناك عدة عوامل تشابه بين احتلال الصليبيين 
والإسر ائيلين لمدينة القدس، يتمثل فن الدور الغربى في الغزوين، إذ أن فكرة الحروب الصليبية بدأت

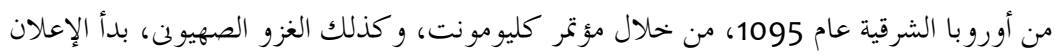

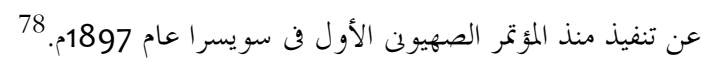

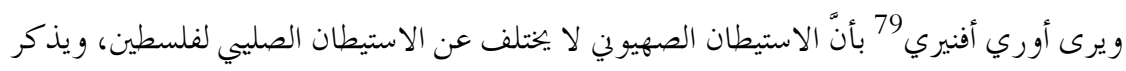

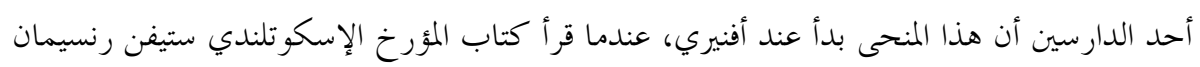

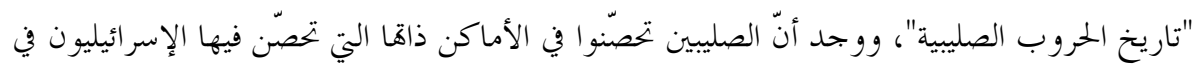

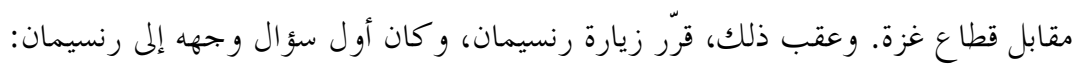

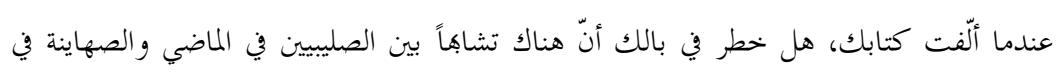

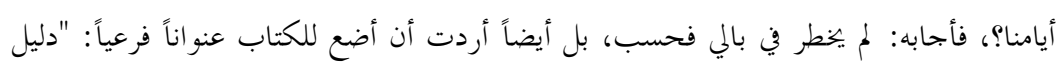

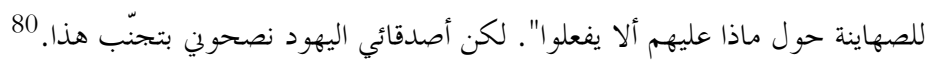

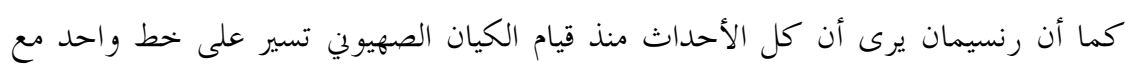

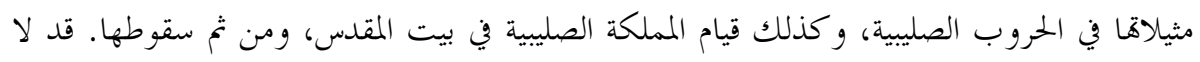

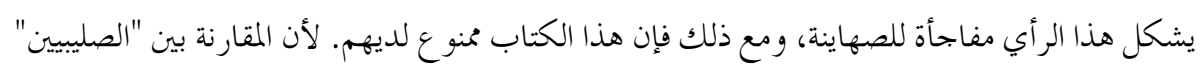

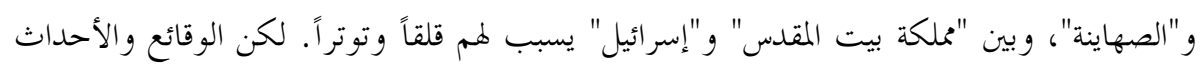
هي التي فرضت هذه المقارنة:

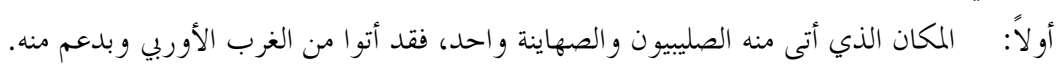

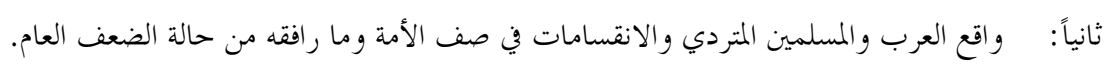

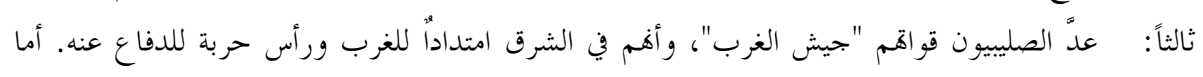

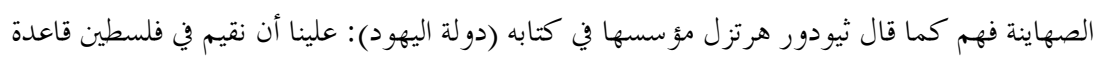

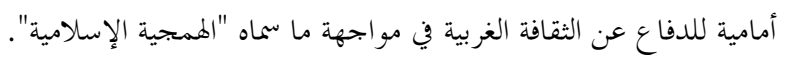

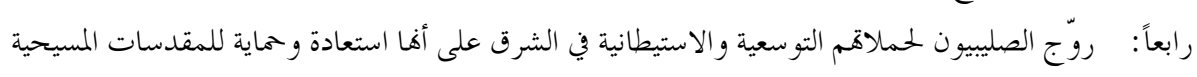

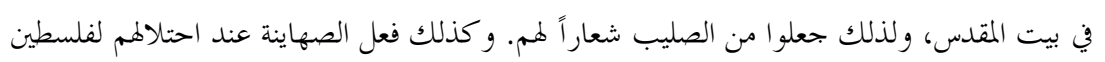

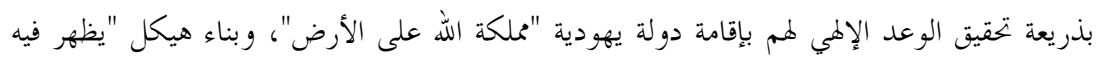

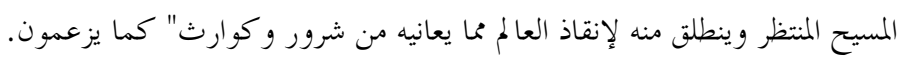

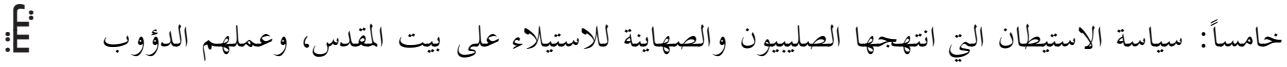

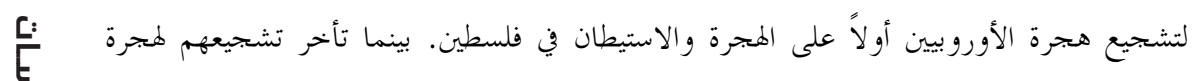

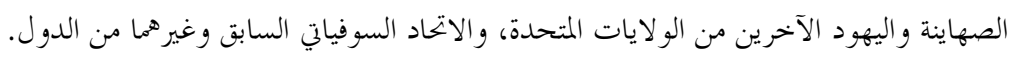

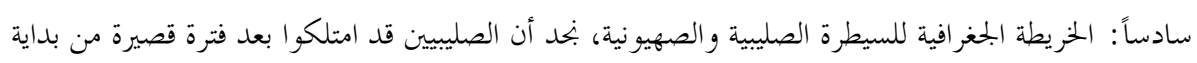

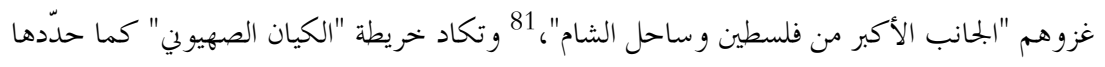


قرار التقسيم الذي أصدرته الأمم المتحدة في 1947 تتشابه إلى حد كبير مع خريطة "ملكة بيت المقدس

$$
\text { الصليبية" التي أنشئت في 1099م. }
$$

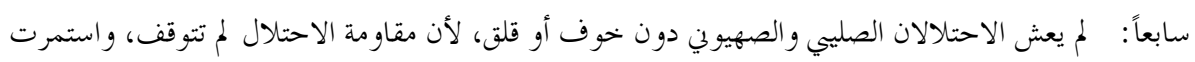

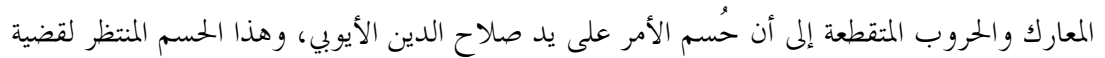
الاستيطان الصهيوني بإذن الله.

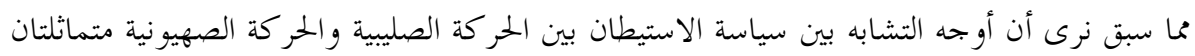

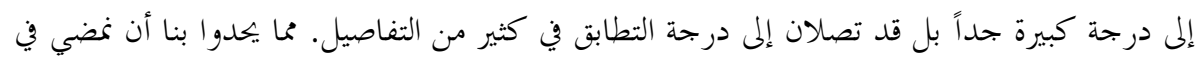
استنباط العبر واستقر اء مرحلة الحملات الصليبية للوقوف على الدروس المستفادة منها في مقاومة المحتل الصهيوني واستعادة الأرض.

\section{الخاتمة}

إن الادعاء بأن هذه المقالة يمكن لها أن تناقش قضية جوهرية في حياة الأمة الإسلامية أمر لا يدعيه عاقل،

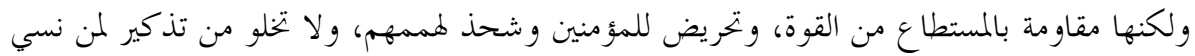

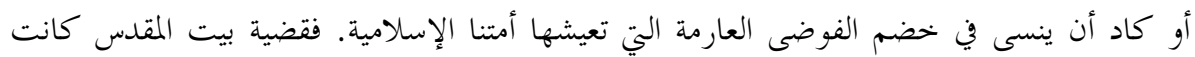

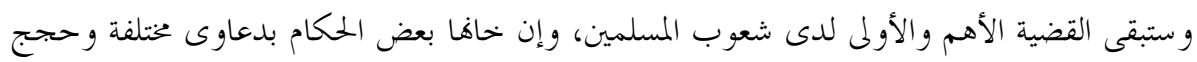

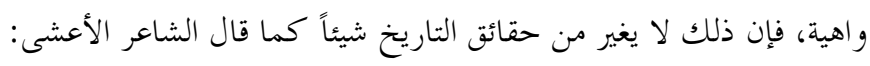

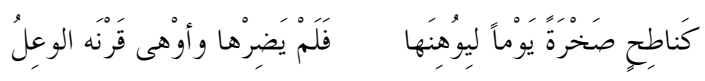

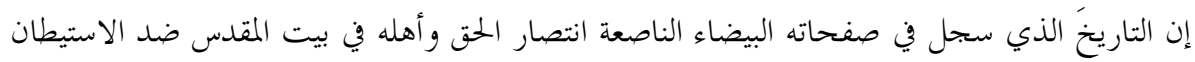

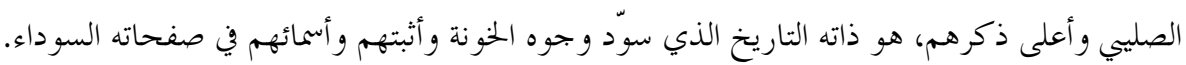
ومن خلال هذه الدراسة نخلص إلى جملة من النتائج ، أهمها:

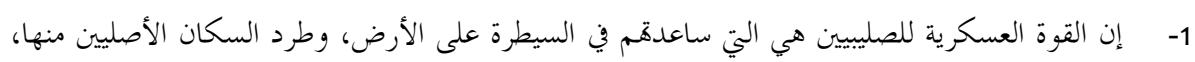

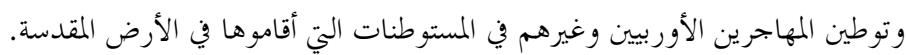

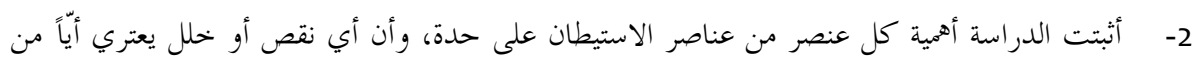

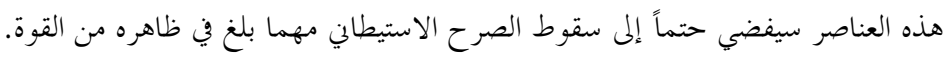

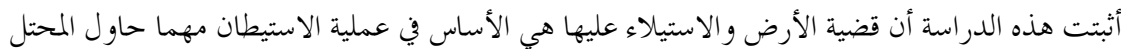
أن يسترها تحت غطاء من دعاوى دينية أو قومية. 4- إن عمليات الاستيطان متلازمة مع عمليات الطرد و التهجير لأصحاب الأرض، تمهيداً لاستقدام المستوطنين

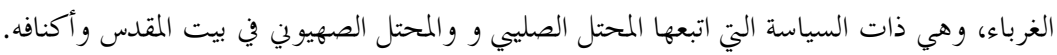


أثنتت هذه الدراسة أنّ وحدة الأمة والعمل الجحادّ من قِبَل أصحاب الأرض مع استمرار المقاومة من أهمّ الأسباب التي أهت عملية الاستيطان الصليي في الأرض المقدسة.

إن تشابه المقدمات في الوقائع التاريخية لا بد لها أن تصل إلى نتائج متماثلة أيضاً، لذا يجب علينا أن نعيد قراءة الأحداث المعاصرة في ضوء حقائق التاريخ، لنصل إلى حلول ناجعة لمشكلاتنا المعاصرة التي تقف عائقاً أمام هوض أمتنا وتحرير بيت المقدس وفلسطين وغيرها من بلاد المسلمين.

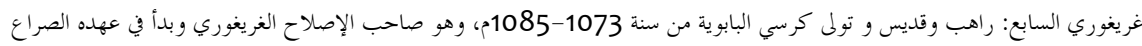

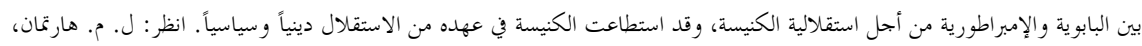

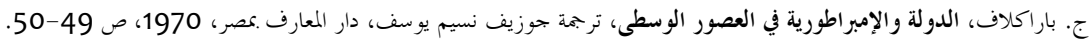

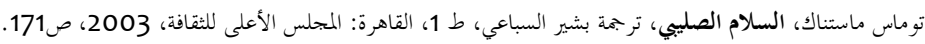

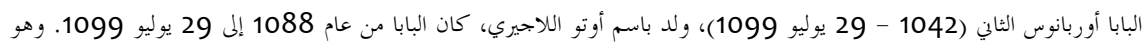

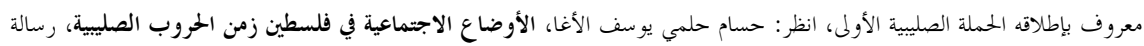

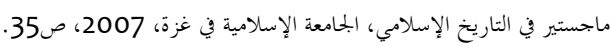

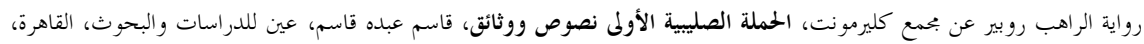

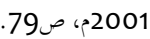

$$
\text { 6 } 5 \text { المصدر السابق، ص79. }
$$

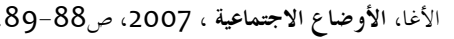

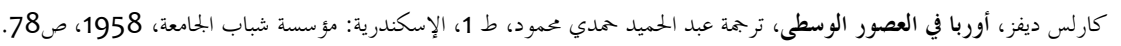

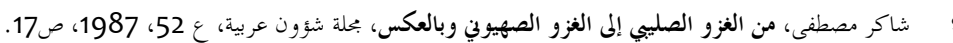

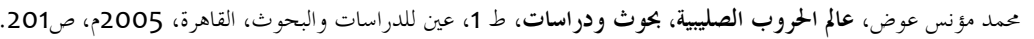
جان ريتشار، تكوين مملكة بيت المقدس اللاتينية وبنيتها، ضمن كتاب: الصراع الإسلامي الفربني على فلسطين، بيروت: مؤسسة الدراسات الفلسطينية، 1994، ص158.

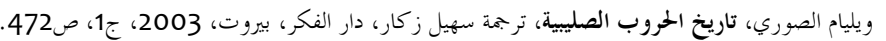
مصطفى الحياري، مدينة القدس زمن الفاطميين والفرنجة، مكتبة عمان، 1994 م، ص ص 199

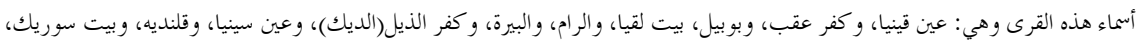

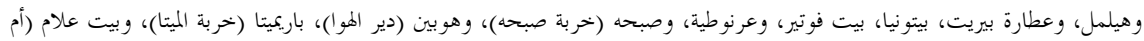

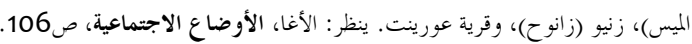
الصوري، تاريخ الحروب الصليبية، ج 1، صن 801، 801، الجحتوري، علية عبد السميع، إمارة الرها الصليبية، الهيئة المصرية العامة للكتاب،

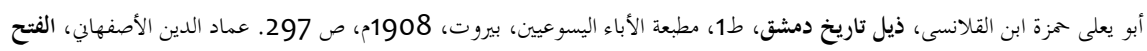

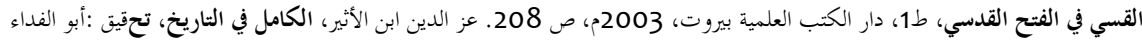
عبد الله القاضي، ط3، دار العلمية، بيروت، الفئ، 1998م، ج 10 ، ص 120 و 184. 
بالار، ميشيل بالار، الحملات الصليبية والشرق اللاتيني في القرن 11-14م، ترجمة بشير السباعي، ط1، عين للدراسات والبحوث الاجتماعية

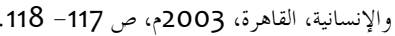
حسين عطية، دراسات في تاريخ الحروب الصليبية، ط1، دار المعرفة الجامعية، الإسكندرية، 2000م، ص303 - 3007 -307، و روجر أف

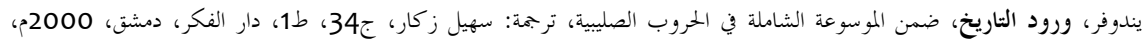
ص228. الصوري، تاريخ، ج2، ص858 هوهاء الدين ابن شداد، النوادر السلطانية والمحاسبة اليوسفية، ط1، دار المنار،القاهرة، 2000م، ص 25-

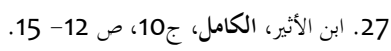

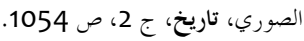
سهيل ز كار، مدخل إلى تاريخ الحروب الصليبية، ط2، دمشق، دار الفكر المعاصر، 1975م، ص 244. Raymound d'Aguiles, Historia Francorum qui ceperunt Iherusalem, Paris 1866, p.300.

ريموند دجيل Raymound d'Aguiles: من المؤرخين الذين عاصروا الحملة الصليبية الأولى. ينظر: جوزيف نسيم يوسف: العرب والروم

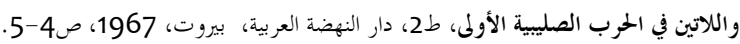

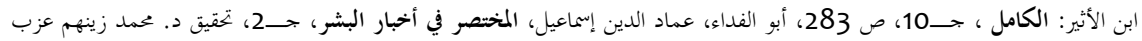

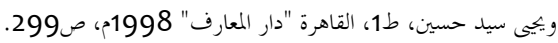
الشارتري، فوشيه الشارتري، تاريخ الحملة إلى القدس، ترجمة زياد العسلي،ط1، دار الشروق، عمان، إن، 1990م، ص 76 ـ الصوري، تاريخ،

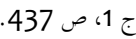
ينظر: امطير، محمد سامي أحمد، الحياة الاقتصادية في بيت المقدس وجوارها في فترة الحروب الصليبية، رسالة ماجستير، كلية الدراسات العليا

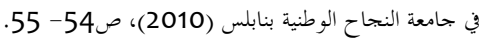

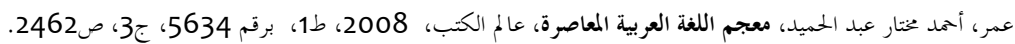

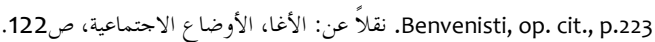

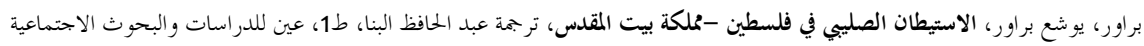

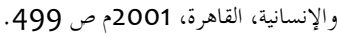
3

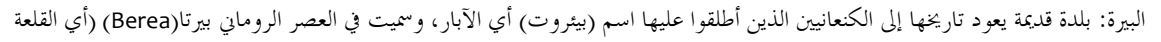

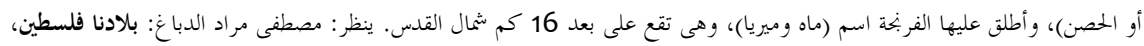

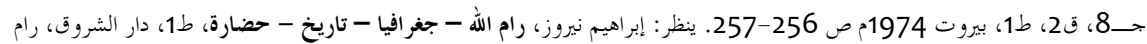
الله، 2004م، ص 81. 33 سلامة، جلال حسني، الاستيطان الصليبي في الأراضي المقدسة 1099-1187م/492-583هـ، رسالة دكتوراة غير منشورة، كلية

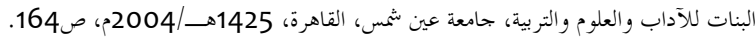
34 35

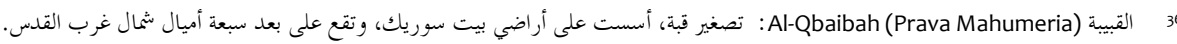
وذكرت القرية في العديد من الوثائق التي ترجع إلى العصر الصليي، يوجد ها في الوقت الحالي كنيسة مهدمة للصليبين.

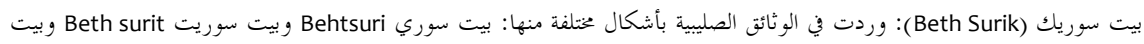

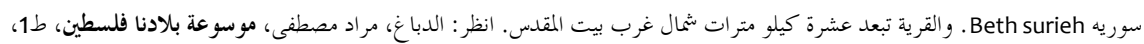

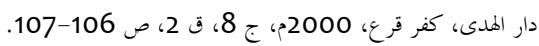
38 39 الرام (Aram) : تقع على بعد خمسة أميال شمال القدس, وفي منتصف المسافة بين قلندية وجبع، وترتفع نهو سبعمائة وثمانين مترًا عن سطح

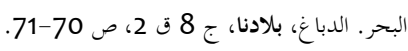


40 البيشاوي، سعيد عبد الله جبريل البيشاوي، الممتلكات الكنسية في مملكة بيت المقدس الصليبية "1099-1291"، دار المعرفة الجامعية،

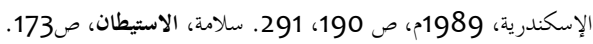

41

42

قرية الزيب: وهي قرية كنعا نية عرفت باسم أكزيب، عرفها الفرنج باسم أمبرت نسبة إلى الفارس الصليي الذي استولى عليها سنة 497 هــــ

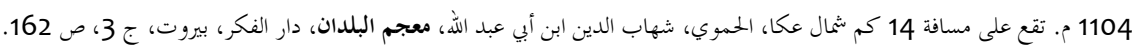

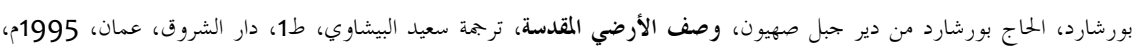

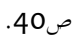

44 44

45 م 44 محد بن أحمد الكتاني ابن جبير، الرحلة المسماة تذكرة بالأخبار في اتفاقيات الأسفار، ط 1،دار الكتب العلمية، بيروت، 2003م، ص

.236

4 46

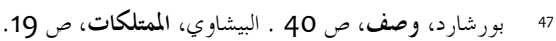

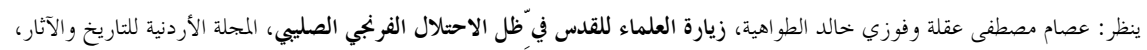

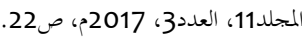
49 الأصفهاني، الفتح، ص 92 و ـ أبو شامه، شهاب الدين أبو محمد، الروضتين في أخبار الدولتين التورية والصلاحية، قدم له وعلق عليه إبراهيم

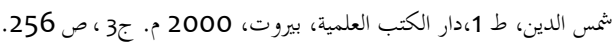

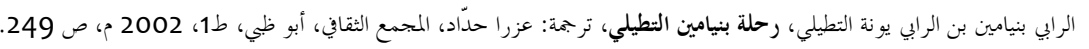
5 5

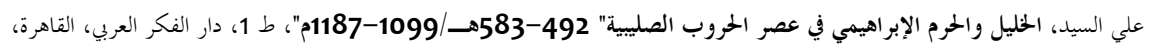
.329 1998 المدني، رشاد عمر، الحياة العلمية في فلسطين في مرحلة الصراع الصليبي الإسلامي "491-690هـ، 1098-1291" رسالة ماجستير

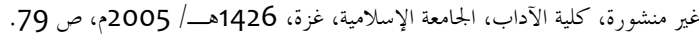

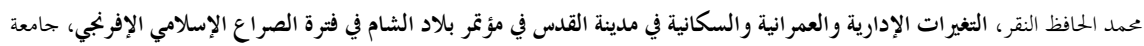

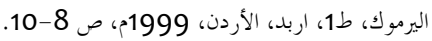

ريموند أجيل، تاريخ الفرنجة غزاة بيت المقدس، ترجمة الردن، حسين محمد عطية، ط 1، دار المعرفة الجحامعية، الإسكندرية، 1990 م، ص244 ـ

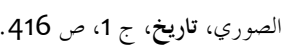
هو مكي بن عبد السلام بن الحسين بن القاسم الأنصاري، مؤرخ ومن الحفاظ والرحالة و كان بحتهدا في طلب العلم، وسمع على كثير من العلماء

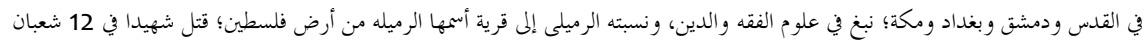

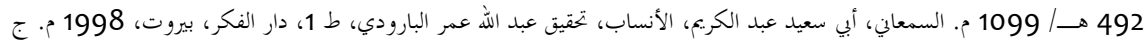

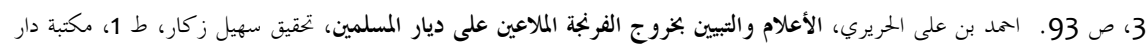

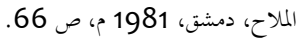

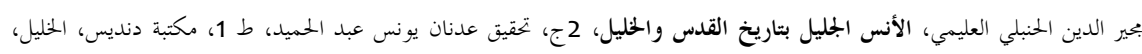

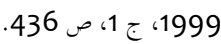

$$
\text { 1999، ج 1. }
$$

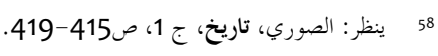
59 المصدر السابق، ج1، ص472. 60 60 61 60 61 62 الشارتري، تاريخ الحملة، ص 109. 


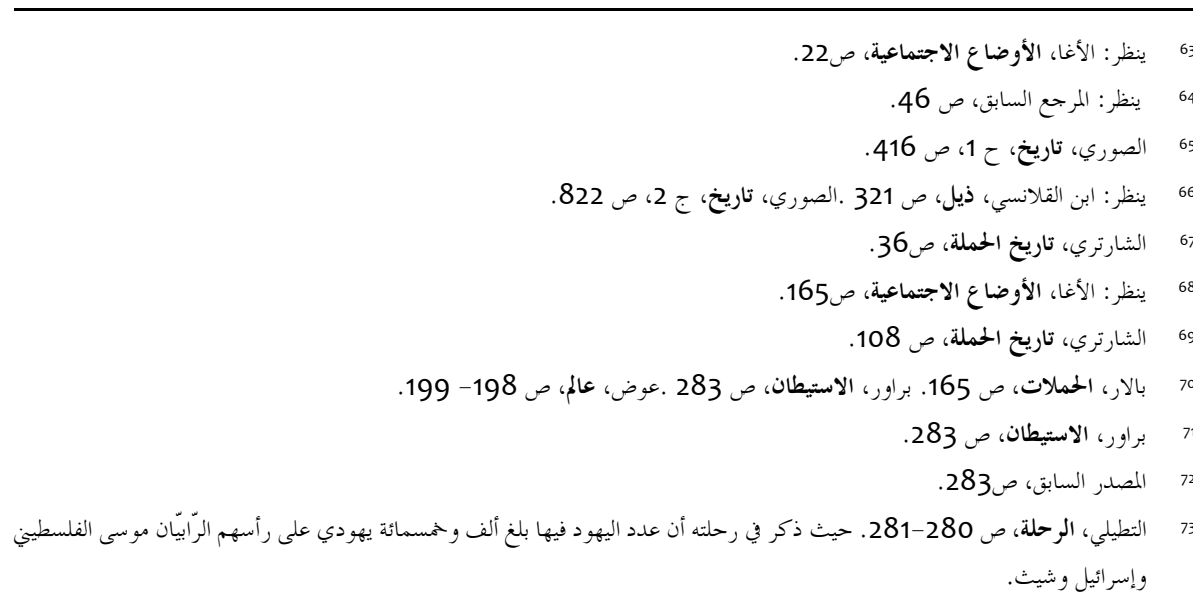

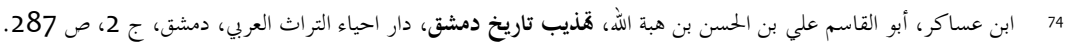

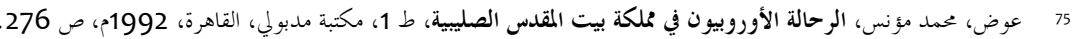

76 76

77 كمال محمد محمد الأسطل، مستقبل اسرائيل بين الاستئصال والتذويب: دراسة حول المشاهة التاريخية بين الغزوة الصليبية والغزوة

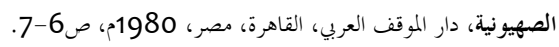

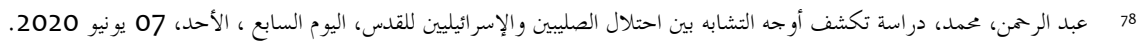

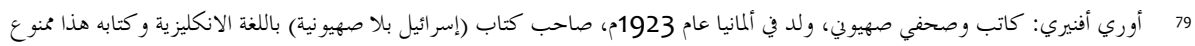

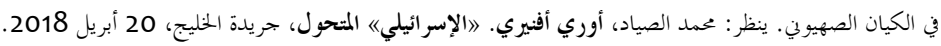

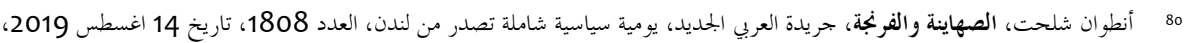

81 السيد على السيد، العلاقات الاقتصادية بين المسلمين والصليبيين. عين للدراسات والبحوث الإنسانية والاجتماعية، القاهرة، 1996 .155.

82 82 